\title{
Review \\ Advanced Processing and Machining of Tungsten and Its Alloys
}

\author{
Samuel Omole ${ }^{1, *} \mathbb{D}$, Alexander Lunt ${ }^{1} \mathbb{D}$, Simon Kirk ${ }^{2}$ and Alborz Shokrani ${ }^{1,3}$ \\ 1 Department of Mechanical Engineering, University of Bath, Bath BA2 7AY, UK; ajg120@bath.ac.uk (A.L.); \\ asc28@bath.ac.uk (A.S.) \\ 2 Culham Centre for Fusion Energy (CCFE), Culham Science Centre, Abingdon OX14 3DB, UK; \\ Simon.Kirk@ukaea.uk \\ 3 Centre for Advanced Design and Manufacturing, University of Bath, Bath BA2 7AY, UK \\ * Correspondence: so444@bath.ac.uk; Tel.: +44-1225-38-6588
}

Citation: Omole, S.; Lunt, A.; Kirk, S.; Shokrani, A. Advanced Processing and Machining of Tungsten and Its Alloys. J. Manuf. Mater. Process. 2022, 6, 15. https://doi.org/10.3390/ jmmp6010015

Academic Editor: Steven Y. Liang

Received: 24 November 2021

Accepted: 17 January 2022

Published: 20 January 2022

Publisher's Note: MDPI stays neutral with regard to jurisdictional claims in published maps and institutional affiliations.

Copyright: () 2022 by the authors. Licensee MDPI, Basel, Switzerland. This article is an open access article distributed under the terms and conditions of the Creative Commons Attribution (CC BY) license (https:// creativecommons.org/licenses/by/ $4.0 /)$.

\begin{abstract}
Tungsten is a refractory metal with the highest melting temperature and density of all metals in this group. These properties, together with the high thermal conductivity and strength, make tungsten the ideal material for high-temperature structural use in fusion energy and other applications. It is widely agreed that the manufacture of components with complex geometries is crucial for scaling and optimizing power plant designs. However, there are challenges associated with the large-scale processing and manufacturing of parts made from tungsten and its alloys which limit the production of these complex geometries. These challenges stem from the high ductile-tobrittle transition temperature (DBTT), as well as the strength and hardness of these parts. Processing methods, such as powder metallurgy and additive manufacturing, can generate near-net-shaped components. However, subtractive post-processing techniques are required to complement these methods. This paper provides an in-depth exploration and discussion of different processing and manufacturing methods for tungsten and identifies the challenges and gaps associated with each approach. It includes conventional and unconventional machining processes, as well as research on improving the ductility of tungsten using various methods, such as alloying, thermomechanical treatment, and grain structure refinement.
\end{abstract}

Keywords: tungsten; ductility; microstructure; powder metallurgy; additive manufacturing; machining

\section{Introduction}

The demand for electricity is increasing at an unprecedented rate. Worldwide economic growth and an increasing global population are expected to result in a doubling of global electricity consumption by 2040 . The electricity share of the total final energy consumption is also expected to increase from 19\% in 2018 to $24 \%$ in 2040 [1]. Concerns about the catastrophic effects of climate change require an increase in demand to be offset by alternative production methods which can reduce and control emissions [2]. Some countries have already set mid-century net-zero targets in a bid to meet the 2015 Paris climate agreement goals [3]. However, according to the recent United Nations Environment Programme (UNEP) emissions gap report, these ambitious targets are not without barriers. Even if these targets were met, the global temperature rise from pre-industrial levels is still on course to be more than $3{ }^{\circ} \mathrm{C}$ this century-well beyond the $2{ }^{\circ} \mathrm{C}$ or the ideal $1.5^{\circ} \mathrm{C}$ set in the Paris agreement [4]. Technological innovations and sustained policy interventions are urgently required on a global scale to reverse this trend.

While renewable energy sources show promise in moving the world towards zero carbon emissions, concerns about their reliability persist. This makes nuclear energy an increasingly valuable source of carbon-free electricity generation [5]. Since the 1950s, nuclear fission has been widely used as a source of electricity. However, concerns over public safety and long-lived radioactive waste have resulted in public outcry and a shift away from this energy generation method [6]. Nuclear fusion, on the other hand, has 
inherent advantages which serve to encourage its adoption in modern energy infrastructure. Amongst other benefits, fusion does not cause harmful emissions and its reactions can be better controlled. Careful design of the reactor leaves room for the provision of efficient, affordable, and safe energy [7]. To realize reliable, large-scale fusion, technological and scientific advances are required in the manufacturing of radiation-resistant materials which can withstand the extreme conditions experienced inside a reactor. One such material is tungsten, which is known for its high density, strength, and thermal conductivity, making it an ideal candidate for plasma facing applications inside a reactor. These applications include its use as divertors and first wall components. Two other characteristics that make tungsten ideal in fusion reactors conditions include its high plasma sputtering erosion resistance and low tritium retention [8,9].

Tungsten belongs to Group 6 of the periodic table along with Molybdenum, Chromium, Seaborgium. It is considered a refractory metal which is the name given to a group of metallic elements that possess extraordinary resistance to heat and wear. Other metals in this group include niobium, tantalum, molybdenum, and rhenium. Tungsten has a very high melting temperature (highest of all known metals in pure form), high density, high elastic modulus, high thermal conductivity, and excellent mechanical properties at elevated temperatures. Table 1 shows the temperature dependency of several of its key properties. These properties have led to tungsten being used for numerous applications.

The rich history of tungsten from the discovery of its ores and compounds to subsequent technically important findings spurred widespread early applications. The discovery of tungsten minerals dates to the middle ages in the tin mines of Saxony-Bohemia and Cornwall, long before the isolation of the element itself [10]. These minerals were infamous for their adverse influence during tin production, as their inclusion led to a reduction in the amount produced [11]. This is the origin of the name "Wolfram" used to acknowledge this yield reduction. While the isolation of tungsten metal was first proposed by Torbern Bergmann in 1781, Juan José de Elhuyar and his brother, Fausto, were the first to prepare the metal in 1783 by reducing tungstic acid with powdered charcoal. Upon isolation, the metal was also named wolfram which remains its official name in both German and Swedish today [10]. Everywhere else, the metal is referred to as tungsten. This is the result of a controversy surrounding its naming, although the International Union of Pure and Applied Chemistry (IUPAC) now officially recognize it as tungsten [12].

The earliest application of tungsten was as an alloying element to produce special steels. From there, it quickly gained prominence as filaments in incandescent bulbs where it replaced carbon filaments. Since then, the material has seen extensive adoption in various fields, including aviation, automotive, electronics, medicine, military, chemicals, and sports. Applications include heating filaments, electron emitters, heat sinks, heating elements, and radiation shields in high-temperature furnaces, kinetic energy penetrators, balancing weights in race cars as well as in aerospace, rotors for the watch industry, heavy-duty electrical contact materials and welding, plasma, and X-ray electrodes, among others $[10,13]$.

Although beneficial for its applications, the properties of tungsten also result in significant challenges during production. The high melting temperature of tungsten makes processing methods, such as casting, unfeasible. Its high ductile-to-brittle transition temperature (DBTT) severely limits its workability at room temperature. This, in turn, limits the performance of manufacturing methods, such as forming and machining [14]. While studies have shown that the workability of tungsten can be enhanced by improving the ductility, the DBTT remains above $200{ }^{\circ} \mathrm{C}$ in most cases. This paper thoroughly investigates the processing and manufacturing methods for commercially pure tungsten (CPW) and its alloys to identify the underlying mechanisms which contribute to the properties of the metal. This is then related to the production challenges and potential opportunities for manufacturing parts from tungsten for engineering applications. 
Table 1. Properties of tungsten where $\mathrm{T}$ is temperature in ${ }^{\circ} \mathrm{C}[14-16]$.

\begin{tabular}{|c|c|}
\hline Property & Title 2 \\
\hline $\begin{array}{l}\text { Density, } \rho\left(\mathrm{kg} / \mathrm{m}^{3}\right) \\
20^{\circ} \mathrm{C} \leq \mathrm{T} \leq 1200^{\circ} \mathrm{C}\end{array}$ & $\left(19.3027-2.3786 \times 10^{-4} \mathrm{~T}-2.2448 \times 10^{-8} \mathrm{~T}^{2}\right) \times 1000$ \\
\hline Hardness [16] & $\begin{array}{c}\text { Brinell (294) } \\
\text { Knoop (318) } \\
\text { Rockwell A (66) } \\
\text { Rockwell C (31) } \\
\text { Vickers (310) }\end{array}$ \\
\hline $\begin{array}{l}\text { Modulus of Elasticity, } \mathrm{E}(\mathrm{GPa}) \\
20{ }^{\circ} \mathrm{C} \leq \mathrm{T} \leq 800^{\circ} \mathrm{C}\end{array}$ & $397.903-2.3066 \times 10^{-3} \mathrm{~T}-2.7162 \times 10^{-5} \mathrm{~T}^{2}$ \\
\hline Average tensile strength, $S_{\mathrm{u}}(\mathrm{MPa})$ at $20^{\circ} \mathrm{C}$ & $\begin{array}{l}1432 \text { (stress-relieved) } \\
380 \text { (recrystallized) }\end{array}$ \\
\hline Average yield strength, $\mathrm{S}_{\mathrm{y}}(\mathrm{MPa})$ at $20^{\circ} \mathrm{C}$ and $0.2 \%$ offset & $\begin{array}{l}1360 \text { (stress-relieved) } \\
94 \text { (recrystallized) }\end{array}$ \\
\hline $\begin{array}{l}\text { Average uniform elongation, } \varepsilon_{\mathfrak{u}}(\%) \text { for stress-relieved conditions } \\
\qquad 300^{\circ} \mathrm{C} \leq \mathrm{T} \leq 700^{\circ} \mathrm{C}\end{array}$ & $-0.1713+9.39 \times 10^{-3} \mathrm{~T}-1.11 \times 10^{-5} \mathrm{~T}^{2}$ \\
\hline $\begin{array}{c}\text { Average total elongation, } \varepsilon_{\mathrm{t}}(\%) \\
500^{\circ} \mathrm{C} \leq \mathrm{T} \leq 2500^{\circ} \mathrm{C} \text { (annealed) } \\
800^{\circ} \mathrm{C} \leq \mathrm{T} \leq 2500^{\circ} \mathrm{C} \text { (stress-relieved) }\end{array}$ & $\begin{array}{c}20.80+5.30 \times 10^{-2} \mathrm{~T}-2.18 \times 10^{-5} \mathrm{~T}^{2} \text { (annealed) } \\
2.35-3.05 \times 10^{-2} \mathrm{~T}+4.99 \times 10^{-5} \mathrm{~T}^{2}-1.44 \times 10^{-8} \mathrm{~T}^{3} \text { (stress-relieved) }\end{array}$ \\
\hline $\begin{array}{l}\text { Average true strain at rupture, } \varepsilon_{\mathrm{tr}}= \\
\qquad \begin{array}{l}\ln \left(\frac{100}{100-\% R A}\right) \\
500{ }^{\circ} \mathrm{C} \leq \mathrm{T} \leq 2500^{\circ} \mathrm{C}\end{array}\end{array}$ & $\begin{array}{c}\text { Average reduction in area, } \% \mathrm{RA}=-4.88+0.1931 \mathrm{~T}-1.13 \times 10^{-5} \mathrm{~T}^{2}+ \\
1.74 \times 10^{-8} \mathrm{~T}^{3} \text { (annealed) }\end{array}$ \\
\hline Poisson's ratio & 0.29 \\
\hline $\begin{array}{l}\text { Specific heat capacity, } \mathrm{C}_{\mathrm{p}}(\mathrm{J} / \mathrm{KgK}) \\
20{ }^{\circ} \mathrm{C} \leq \mathrm{T} \leq 1000{ }^{\circ} \mathrm{C}\end{array}$ & $128.308+3.2797 \times 10^{-2} \mathrm{~T}-3.4097 \times 10^{-6} \mathrm{~T}^{2}$ \\
\hline $\begin{array}{l}\text { Thermal conductivity, } \lambda(\mathrm{W} / \mathrm{mK}) \\
20{ }^{\circ} \mathrm{C} \leq \mathrm{T} \leq 1000^{\circ} \mathrm{C}\end{array}$ & $174.9274-0.1067 \mathrm{~T}+5.0067 \times 10^{-5} \mathrm{~T}^{2}-7.8349 \times 10^{-9} \mathrm{~T}^{3}$ \\
\hline Melting point $\left({ }^{\circ} \mathrm{C}\right)[14]$ & 3423 \\
\hline Boiling point $\left({ }^{\circ} \mathrm{C}\right)[16]$ & 5900 \\
\hline $\begin{array}{l}\text { Coefficient of linear thermal expansion, } \alpha\left(10^{-6} \mathrm{~K}^{-1}\right) \\
\qquad 20^{\circ} \mathrm{C} \leq \mathrm{T} \leq 1200^{\circ} \mathrm{C}\end{array}$ & $3.9225+5.8352 \times 10^{-4} \mathrm{~T}+5.7054 \times 10^{-11} \mathrm{~T}^{2}-2.0463 \times 10^{-14} \mathrm{~T}^{3}$ \\
\hline
\end{tabular}

The article takes a holistic approach by bridging the gap between an understanding of tungsten as a metal and its various production routes. It begins with an explanation of the microstructure of tungsten together with methods used to improve ductility. Processing methods are generally used to produce near-net-shaped parts within required tolerances. Examples include powder metallurgy and additive manufacturing which are presented in this review. Powder metallurgy is currently the most widely used, and therefore a discussion of the key processes has been provided. An overview of the additive manufacture of tungsten has also been presented in reference to novel technologies, such as wire arc additive manufacturing (WAAM) and laser-based techniques. Other technologies, such as chemical vapor deposition, physical vapor deposition, and plasma spraying, have been included for completeness. However, these techniques are most suited for coating applications, rather than bulk manufacture. The application of non-conventional machining, including electro discharge machining (EDM) and electro chemical machining (ECM), as well as water jet cutting, laser cutting, and laser drilling, have been investigated. Challenges associated with the large-scale and widespread adoption of these techniques were provided. Conventional machining methods for tungsten are not fully established. There is a clear gap in terms of cutting tool geometry and cutting parameters. The paper concludes with a discussion comparing these insights and suggests potential future avenues for research into the manufacturing of tungsten. 


\section{Microstructure and Properties of Tungsten}

In this section, the microstructure of tungsten and its impact on mechanical properties are presented. Existing methods which have been developed to enhance the ductility of tungsten to improve manufacturability are explained in detail.

\subsection{Microstructure of Tungsten}

Tungsten has a body-centered crystalline (BCC) crystal structure. In BCC structures, slip can occur on either the $\{110\}$ (Figure 1), $\{112\}$, or $\{123\}$ planes, which is distinct from the behavior of face-centered cubic (FCC) lattices where slip typically only occurs on the $\{111\}$ planes. The preferred slip plane in BCC materials depends on several factors including the sample preparation, deformation type, strain rate, temperature, and alloy chemistry [17]. Although these factors influence slip characteristics, the BCC lattice of tungsten means that, in all cases, it is not a close-packed structure. Of all the available slip planes, the $\{110\}$ are the most closely packed as their slip directions have the highest linear atomic density. For this reason, the $\{110\}$ planes are the dominant slip planes in tungsten $[18,19]$.

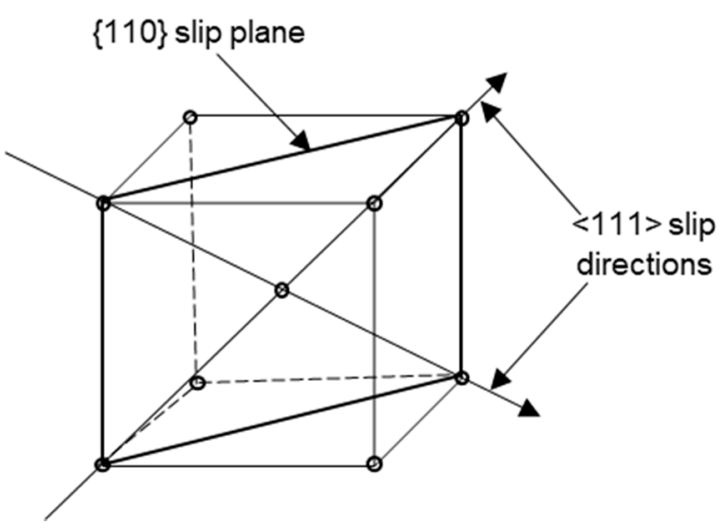

Figure 1. A reduced-sphere unit cell representation of the dominant slip system in a BCC crystal structure. Adapted with permission from Liu [19]. Copyright 2005 ASM International.

The plastic deformation response of tungsten is governed by the mobility of the nonplanar $1 / 2<111>$ screw dislocation [17]. The spread of these dislocation cores into planes of the $<111>$ zone was first suggested by Hirsch [20] which for tungsten, along with other BCC crystals, leads to a very high lattice friction (Peierls) stress [21]. A perfect $1 / 2<111>$ screw dislocation is believed to dissociate onto three different $\{110\}$ or $\{112\}$ slip planes. Since the core of the $1 / 2<111>$ screw dislocation is spread onto three different planes, the screw dislocation cannot easily slip on any of these directions. At the macroscale, this ultimately limits the material ductility [22].

The dominant failure mechanism of tungsten is intergranular fracture [23]. According to Gludovatz et al. [24], for CPW samples ( $>99.97 \%$ ), up to $95.9 \%$ of the fracture surfaces are intergranular. Poor cohesion of grain boundaries is typically due to impurities located at these boundaries, and this has a significant role on the likelihood of failure at these locations. Experimental analysis has revealed that these impurities can be rich in carbon, oxygen, potassium, and phosphorus amongst other elements [24-26]. For example, Joshi and Stein [25] observed that the segregation of phosphorus to the grain boundaries was directly related to embrittlement. The amount of segregation was also reliant on the grain size, such that the larger the grain, the greater the concentration of phosphorus at the boundary and the higher the embrittlement. On the contrary, Gludovatz et al. [24] investigated the influence of impurities on the fracture behavior of W. It was concluded that the occurrence of grain boundary fracture is not always due to impurity-induced embrittlement. Other factors which can affect the fracture behavior of tungsten include the size and shape of the grains, as well as the amount of deformation and density of dislocations within the grains [24]. This topic is worthy of further investigation, and ongoing research is being 
dedicated to improving the understanding of the impact of grain boundaries impurities on the brittleness of tungsten.

The brittleness of tungsten manifests itself in its high DBTT. The DBTT serves as a literal transition point to the ductile behavior from a hitherto inherent brittle material behavior or vice-versa. Figure 2 shows the temperature dependence of the flow stress of high-purity single and polycrystal tungsten tested at room temperature and at $400{ }^{\circ} \mathrm{C}$. Significant ductility can be seen for both materials at $400{ }^{\circ} \mathrm{C}$ relative to room temperature, demonstrating that the DBTT lies between $25{ }^{\circ} \mathrm{C}$ and $400{ }^{\circ} \mathrm{C}$. Figure 2 also depicts a prominent feature of BCC metals in which there is a rapid increase in flow stress with decreasing temperature [27].

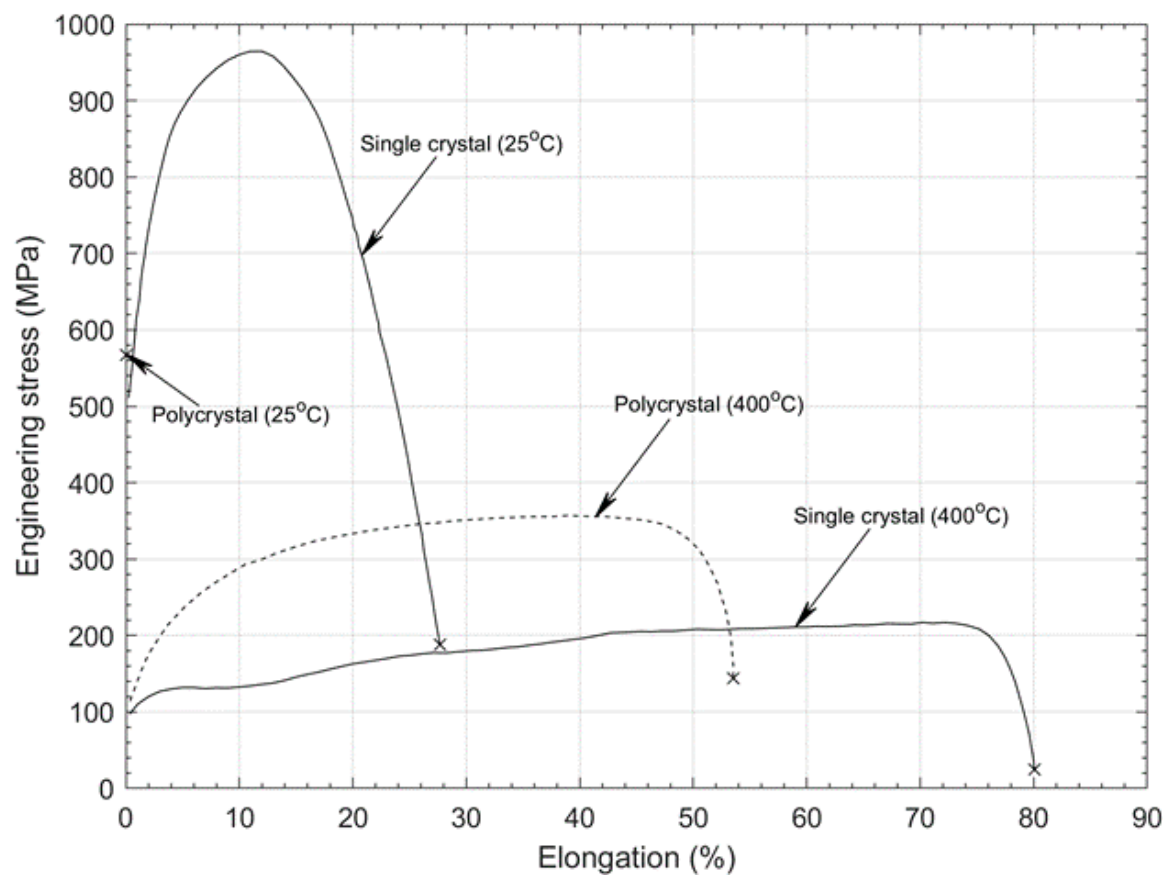

Figure 2. Stress-strain curve of polycrystalline and single-crystal tungsten at a strain rate of 0.02/ $\mathrm{min}$ [27]. Adapted with permission from Snead et al. [14]. Copyright 2019 Elsevier.

Three-point bending tests of smooth bars of CPW was performed by Aguirre et al. [28] to further refine the precision of the DBTT range of tungsten to between $200{ }^{\circ} \mathrm{C}$ and $400{ }^{\circ} \mathrm{C}$. The load-displacement curves at different temperatures from this study are shown in Figure 3, in which the brittle transition below $400{ }^{\circ} \mathrm{C}$ is clearly evident. The study was further validated by Faleschini et al. [29] who identified $400^{\circ} \mathrm{C}$ as the DBTT. Despite these similarities, in general, it should be noted that the transition temperature is neither fixed nor an intrinsic property of tungsten. Its precise value is influenced by parameters such as cold work, grain size, impurities, and the tensile strain rate during deformation [30,31].

\subsection{Methods for Improving the Ductility of Tungsten}

The high strength, DBTT, and brittleness of tungsten are major issues during the manufacturing and use of tungsten, specifically for structural applications. The operating temperature window, which is typically bound by the DBTT and recrystallisation temperature, is much higher than in conventional metals. As an example, the optimal operating window of the thimble and cooling unit of a modular He-cooled divertor should be between $600{ }^{\circ} \mathrm{C}$ and $1300{ }^{\circ} \mathrm{C}$ in order to ensure reliability during use [32]. Hence, the development of tungsten and tungsten alloys with a DBTT of about $600{ }^{\circ} \mathrm{C}$ or lower is crucial for this application. There have been significant research efforts directed towards improving the ductility and decreasing the DBTT of tungsten within the past few decades. Thermomechanical processing, alloying, and grain refinement are methods which have 
been used to improve the ductility of tungsten by modifying the microstructural influence on the macroscale material response [33].

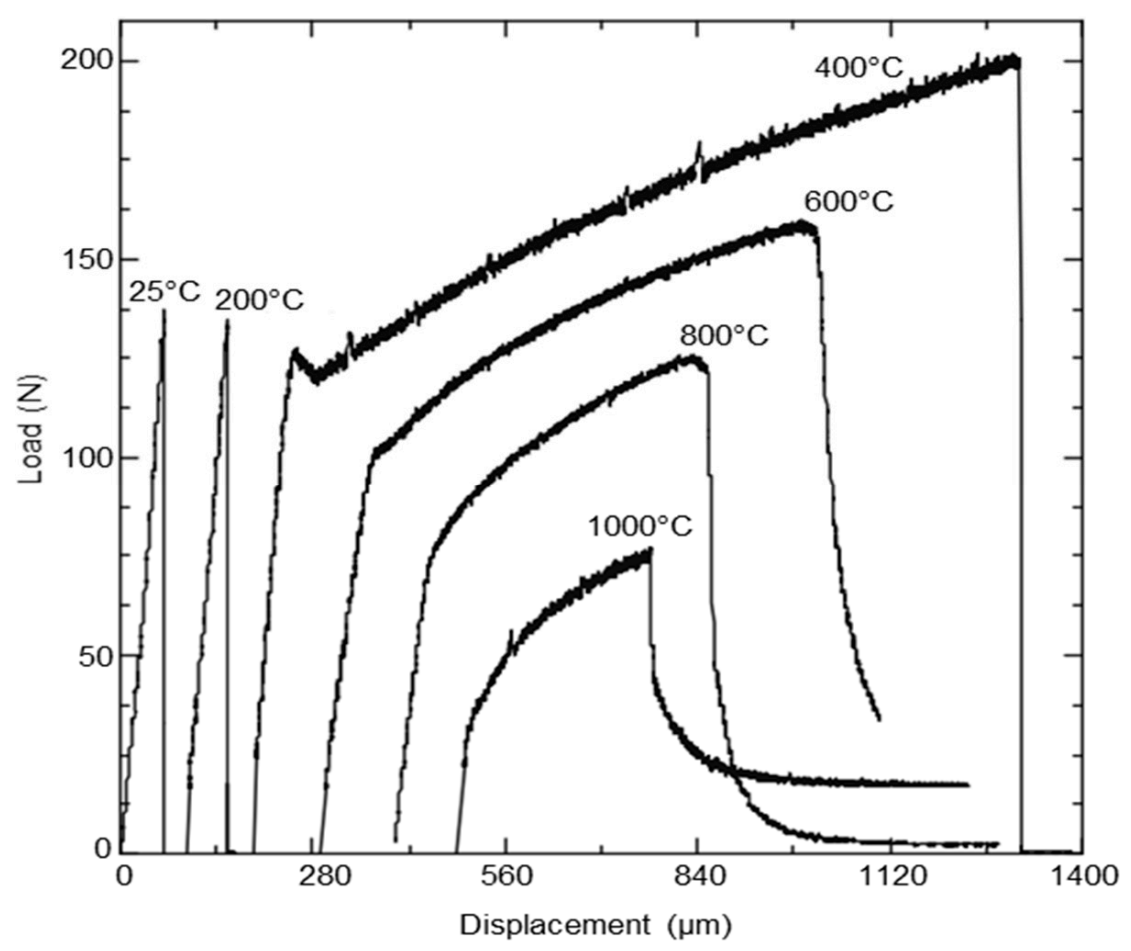

Figure 3. Load-displacement curves from bending tests on smooth bars of pure tungsten at different temperatures [28]. Adapted with permission from Aguirre et al. [28]. Copyright 2009 Springer Nature.

Thermomechanical processing is a hot working method that involves the use of a range of potential high-temperature deformation techniques, which are typically performed below the recrystallisation temperature. Unlike most metals, the ductility of tungsten has been shown to increase following deformation processes (such as rolling, forging, and swaging) or severe plastic deformation techniques (such as equal channel angular pressing and high-pressure torsion) [10]. Shen at al. [34] reported a reduction in the DBTT through hot-rolling and hot-forging. In their study, the materials were hot-rolled and hot-forged between 1450 and $1650{ }^{\circ} \mathrm{C}$ and between 1550 and $1700{ }^{\circ} \mathrm{C}$, respectively. The hot-rolled specimen was found to be more ductile with a DBTT of $250-300{ }^{\circ} \mathrm{C}$ compared to $350{ }^{\circ} \mathrm{C}$ for the hot-forged sample. Despite these improvements, the initial DBTT of the undeformed material was not reported, so the percentage improvement relative to a baseline cannot be determined precisely. The influence of the anisotropic microstructure on fracture behavior and DBTT was also reported by Rupp et al. [35] who fabricated samples from rolled and sintered rods. Pre-crack notches were orientated either parallel, radial, or tangential to the rolling direction, as shown in Figure 4. Using three-point bending tests, the tangentially oriented (type III) specimens showed higher fracture toughness in the brittle regime while also having a lower transition temperature of $275^{\circ} \mathrm{C}$.

Reiser et al. [36] further confirmed this anisotropic material response by measuring the DBTT of cold-rolled and hot-rolled samples in both parallel and transverse orientation to the rolling direction using Charpy impact tests. For the hot-rolled sample, the transition temperature decreased from $475^{\circ} \mathrm{C}$ for the transverse-oriented sample to $375^{\circ} \mathrm{C}$ for the parallel-oriented one. Similarly, for the cold-rolled samples, the DBTT decreased from $250{ }^{\circ} \mathrm{C}$ to $125^{\circ} \mathrm{C}$ as the orientation changed from transverse to parallel. 


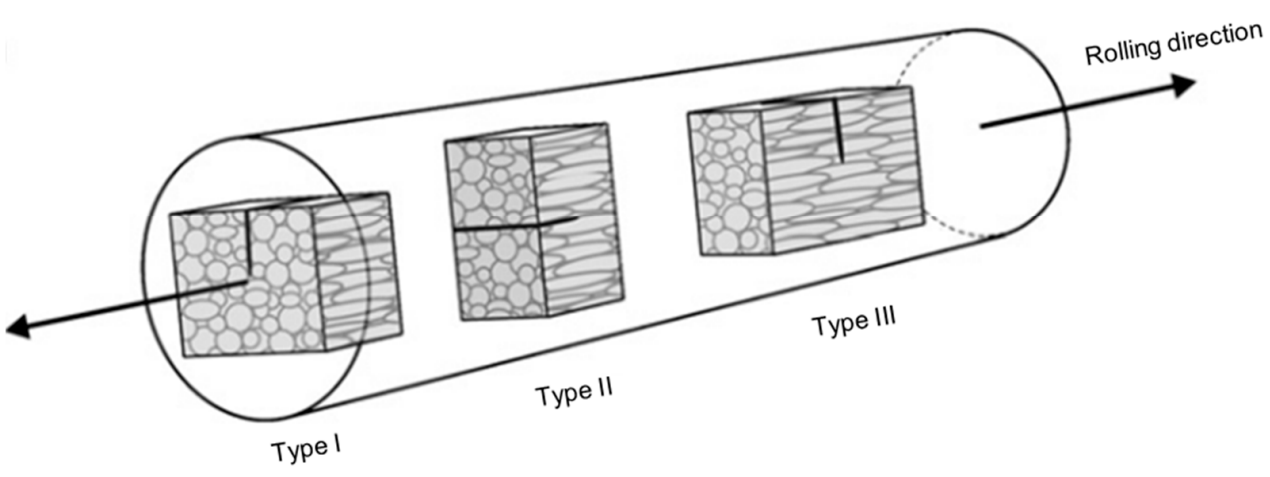

Figure 4. Schematic of the specimens with the different crack orientations with the crack front parallel (type I), radial (type II) and tangential to the rolling direction (type III) [35]. Adapted with permission from Rupp et al. [35]. Copyright 2010 Elsevier.

Low-temperature rolling of tungsten has been shown to increase dislocation density, create more low angle grain boundaries, enhance strength, and lower the DBTT in tungsten [36,37]. A study by Reiser et al. [36] also showed that cold rolling can improve the ductility of tungsten, with an improvement greater than that seen in the hot rolling performed on their samples. Cold and hot working are performed at temperatures below and above recrystallisation temperatures for most metals, respectively. For tungsten, however, the metal is technically cold-worked as the forming process temperature is limited by the recrystallisation temperature, despite the very high temperatures applied. Reiser et al. [36] hot-rolled the material above $1200^{\circ} \mathrm{C}$ while maintaining the temperature below $1200^{\circ} \mathrm{C}$ for the cold-rolled sample. In terms of the effect of temperature, it is apparent that the lower the processing temperature, the lower the DBTT. This was, in fact, a deduction from the study by Reiser et al. [36]. Wei and Kecskes [37] also confirmed this in their study where rolled tungsten samples were found to be more ductile at lower rolling temperatures in tensile testing. This is shown in Figure 5 where the original unrolled sample E possessed no ductility at all and Sample F, rolled at $400{ }^{\circ} \mathrm{C}$, has the highest strength and ductility. The effect of temperature was further highlighted by the behavior of sample D. Its subsequent rolling to $800{ }^{\circ} \mathrm{C}$ from $500{ }^{\circ} \mathrm{C}$ worsened the ductility (comparing samples $\mathrm{C}$ and $\mathrm{D}$ ) and diminished the initial benefits gained.

Mechanical deformation can result in microstructural refinement and lead to a reduction in the DBTT. Figure 6 compares the microstructure of the undeformed (E) and deformed (B) tungsten samples in Figure 5 with the effect of deformation clearly visible in the refined microstructure.

The higher the degree of deformation, the lower the DBTT. For example, an "as-rolled" tungsten sheet can have a DBTT between 100 and $200{ }^{\circ} \mathrm{C}$, while fine wires or foils were even reported to be ductile at room temperature [10]. The impact of the degree of the deformation was studied by Zhang et al. [38] who investigated the thermal and mechanical properties of a 30-mm-thick tungsten sample under different rolling reductions. The DBTT for the $90 \%$ and $60 \%$ rolled samples were estimated to be $527^{\circ} \mathrm{C}$ and $577^{\circ} \mathrm{C}$, respectively. This change in temperature was significantly smaller than that expected for such extreme differences in deformation. It should also be noted that both values are high DBTTs when compared to other studies, although this can be attributed to the post-deformation annealing stage applied to these samples. 


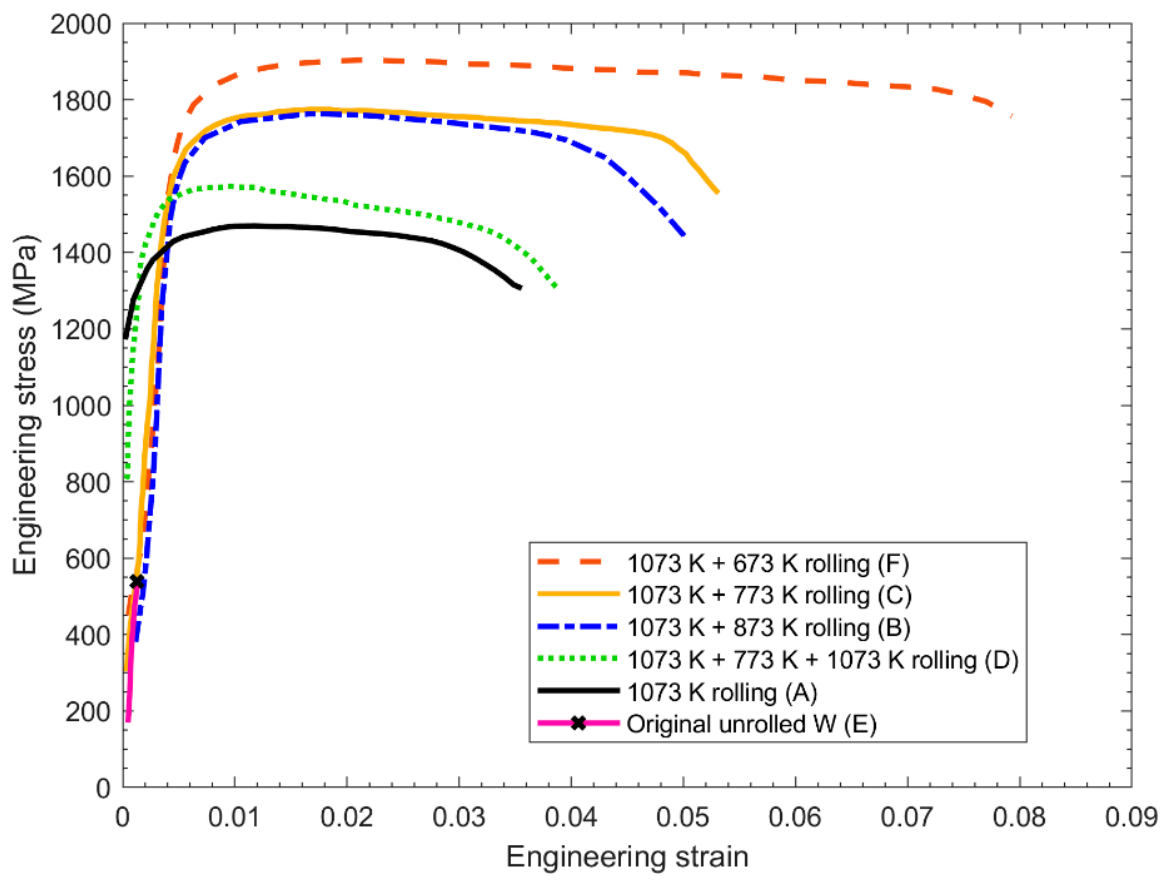

Figure 5. Engineering stress-strain curves of different tungsten samples rolled at different temperatures [37]. Adapted with permission from Wei and Kecskes [37]. Copyright 2008 Elsevier.
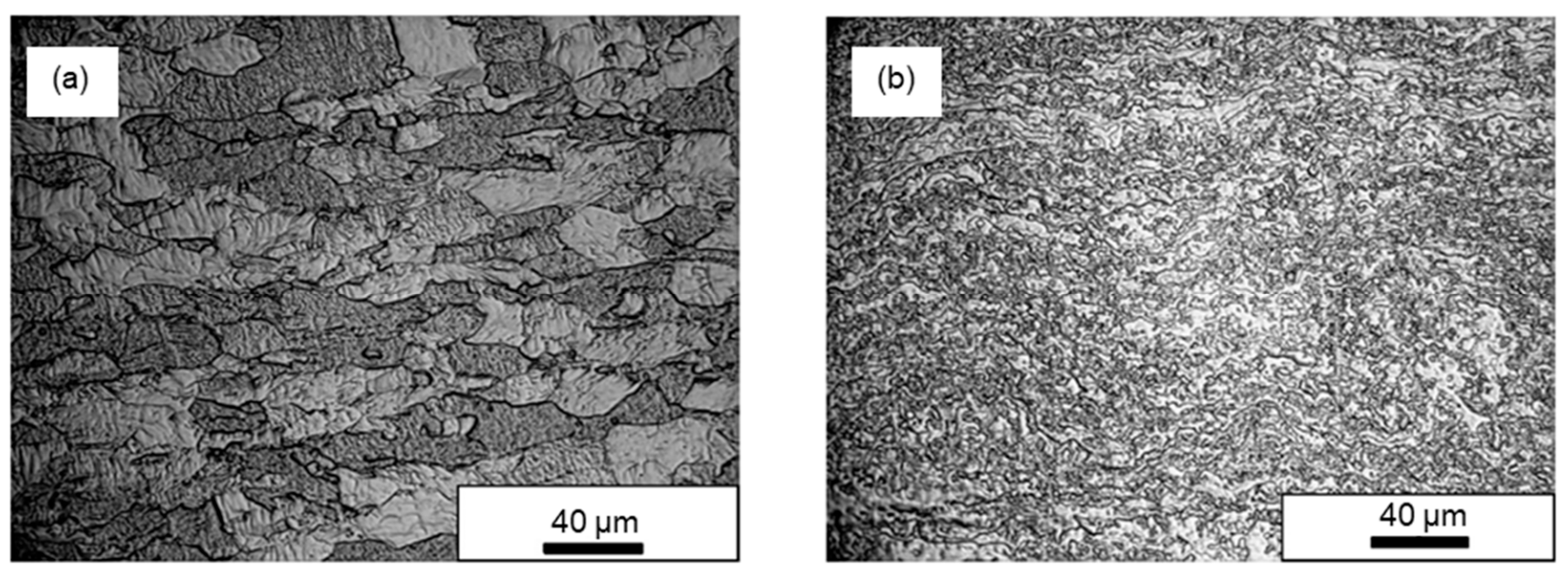

Figure 6. Optical micrograph of the tungsten samples showing the microstructure for (a) undeformed coarse-grained sample; (b) sample rolled at initial and final temperatures of $800{ }^{\circ} \mathrm{C}$ and $600{ }^{\circ} \mathrm{C}$, respectively [37]. Adapted with permission from Wei and Kecskes [37]. Copyright 2008 Elsevier.

The conventional Hall-Petch expression $[39,40]$ relates grain size to the strength of a metal, such that strength increases with a reduction in the average grain size. This can be used to predict the effect of grain refinement, due to deformation, on the strength of tungsten. The synergies between hardness $H$ and strength, as well as challenges in performing tensile testing on tungsten, have led to the use of indentation testing to study this effect. By following this approach, Vashi et al. [41] provided the following analogous Hall-Petch relation for tungsten,

$$
H=H_{0}+K_{H} l^{-1 / 2}
$$

where $H_{0}$ is the hardness of a single crystal tungsten $\left(350 \mathrm{~kg} / \mathrm{mm}^{2}\right), K_{H}$ is the Hall-Petch coefficient $\left(10 \mathrm{~kg} / \mathrm{mm}^{3 / 2}\right)$, and $l$ is the grain size in $\mathrm{mm}$. This hardness-grain size relation 
shows that the hardness increases significantly as the grain size is reduced. By extension, the strength and ductility are improved with refined microstructures.

In contrast to most metals, annealing and recrystallisation of deformed tungsten reduces ductility due to grain growth and coarsening. Grain coarsening reduces the internal grain boundary area and causes an increase in the concentration of grain boundary impurities. Since the grain boundaries are stronger when the impurities are distributed over a larger area, the ductility decreases by annealing above tungsten's recrystallisation temperature. For this reason, the improvements gained from mechanical working of tungsten can be lost by a subsequent annealing step. Therefore, in order to retain the improvements in ductility, annealing must be avoided for tungsten during or after deformation [42,43].

Alloying tungsten with rhenium is a popular method for improving ductility other than hot working. It is widely regarded that the formation of a solid solution of tungsten and rhenium can reduce the Peierls stress, resulting in improved mobility of the $1 / 2<111>$ screw dislocation. This also makes additional slip planes available (including $\{112\}$ planes), thereby increasing the total number of potential slip planes for dislocation transport [44,45]. Many studies have reported an improvement in ductility and fracture toughness due to rhenium alloying. The earliest study was by Geach and Hughes [46] where the addition of rhenium resulted in a more workable material. They observed that an arc-melted tungsten-rhenium alloy can achieve an $11 \%$ reduction in thickness by cold rolling. In contrast, the CPW sample they trialed cracked at the beginning of the rolling process. Mutoh et al. [47] compared the fracture toughness of tungsten specimens containing 0,5 , and $10 \mathrm{wt} \%$ of rhenium. Aside from a reduction in the transition temperature and delayed recrystallisation, rhenium improved the high-temperature toughness of tungsten. It was also found that the fracture toughness increases with the concentration of rhenium in the alloy. Wurster et al. [48] also showed that rhenium alloying increases the fracture toughness of tungsten via high-temperature vacuum fracture experiments. The recrystallized alloys even outperformed the pure recrystallized samples in toughness by about a factor of 3 . Watanabe et al. [49] quantified improvements in mechanical properties of $\mathrm{W}-3 \%$ Re compared to CPW. The alloy showed 5-30\% more strength, $10-35 \%$ higher total elongation, and a reduction in the DBTT by $100{ }^{\circ} \mathrm{C}$. In general, rhenium solid solution alloying of tungsten improves its plastic properties and delays recrystallisation. This can be attributed to the increased solubility of interstitials, such as carbon, nitrogen, sulphur, and phosphorus in the alloy. These interstitials are redistributed within the lattice from low-energy positions, such as dislocations and grain boundaries [10].

Despite this enormous potential, the high cost of rhenium is a major disadvantage which limits its widespread use. While the DBTT, fracture toughness, and recrystallisation are positively influenced by rhenium, its effect on other mechanical properties must also be considered. For example, Klopp [50] showed that creep properties vary with rhenium content. In their study, high-temperature step-load creep tests were performed on tungsten samples with different rhenium compositions. The analysis showed that samples with $24 \%$ and $26 \%$ rhenium were considerably weaker in creep than samples with $9.1 \%$ rhenium, despite having similar tensile strengths. Furthermore, in fusion applications in particular, rhenium addition must be restricted to fulfil the low activation requirements and to avoid the formation of the hard and brittle $\sigma$-phase [51]. The significant transmutation of rhenium to osmium under neutron irradiation also leads to the production of high-level wastes with high disposal ratings [52]. These limitations with rhenium have prompted research into other metals including nickel, molybdenum, titanium, tantalum, and vanadium to achieve similar results of improving ductility.

Fang et al. [53] investigated the effect of nickel alloying ( $\leq 1 \%$ by weight) on the mechanical properties of $\mathrm{CPW}$, including ductility and fracture toughness. The presence of nickel was found to increase ductility (compared to the as-sintered CPW) regardless of the testing temperature. The fracture toughness was also found to increase by up to $92 \%$ at room temperature, hence indicating the beneficial effect of nickel in reducing the DBTT. The authors attributed this improvement to the microstructural effects of nickel 
(increased fracture energy due to the introduction of a ductile phase) and strengthening of the grain boundaries.

Ren et al. [54] reported the effects of solid solution alloying of tungsten with $4.65 \mathrm{wt} \%$ molybdenum, including an increase in hardness and toughness together with an improvement in ductility. On the other hand, Patra et al. [55] showed that the addition of molybdenum ( $30 \mathrm{wt} \%$ ) did not enhance ductility, but the alloy required the introduction of nickel and $\mathrm{Y}_{2} \mathrm{O}_{3}$ to achieve improved mechanical properties.

Aguirre et al. [28] showed that the presence of titanium did not reduce the DBTT of polycrystalline tungsten because the titanium did not form a solid solution with tungsten. Instead, this led to the segregation of titanium at the grain boundaries or the formation of titanium-rich inclusions, as shown in Figure 7. Tungsten-titanium specimens tested at $600{ }^{\circ} \mathrm{C}$ or below showed no trace of plastic deformation despite having improved mechanical properties (compared with $\mathrm{CPW}$ and $\mathrm{W}-\mathrm{Y}_{2} \mathrm{O}_{3}$ ) at elevated temperatures (up to $800{ }^{\circ} \mathrm{C}$ ). In contrast, plastic deformation was observed in $\mathrm{CPW}$ at $400{ }^{\circ} \mathrm{C}$ and above.
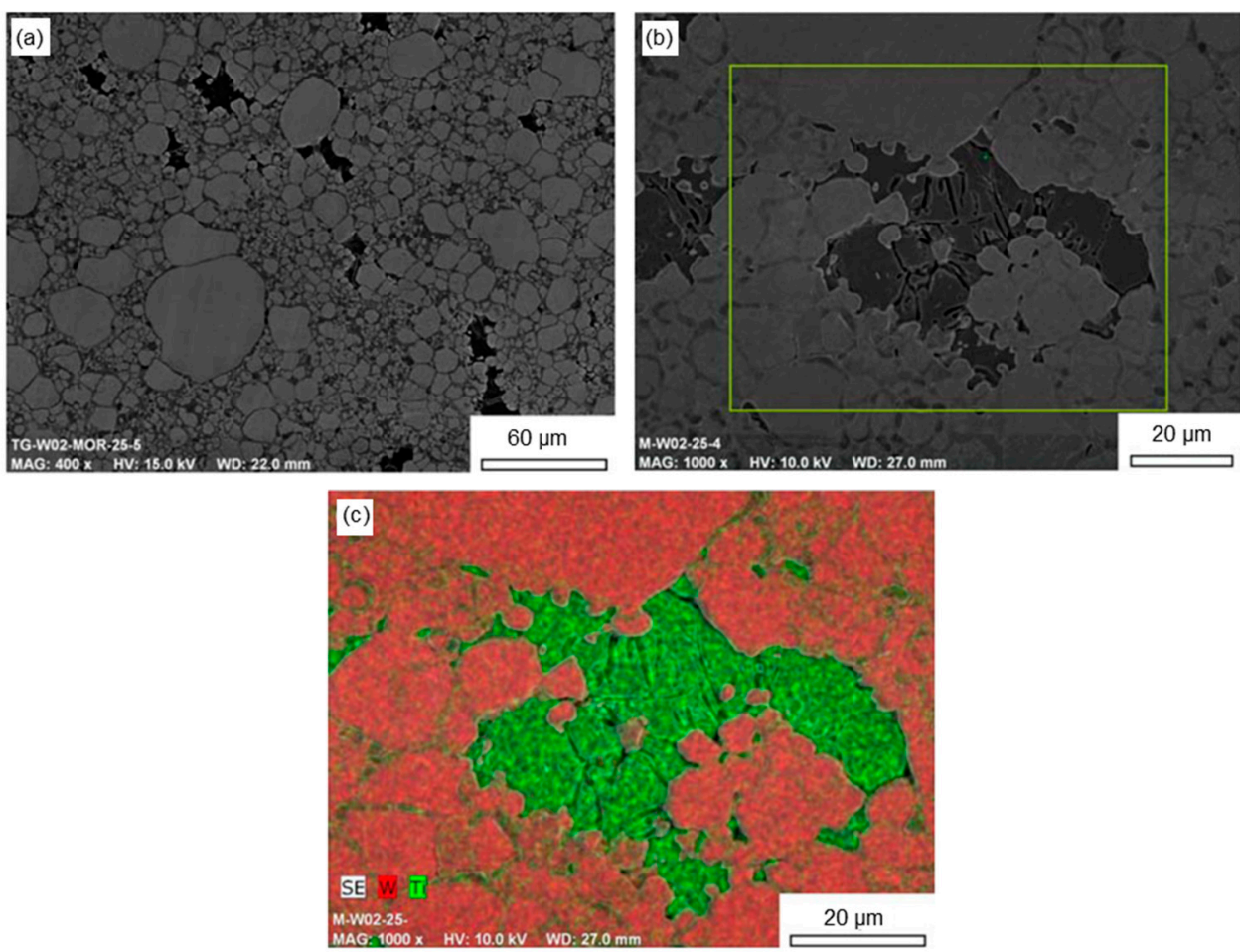

Figure 7. (a) Scanning electron micrograph of a polished and etched cross-section of tungstentitanium alloy where darker regions represent titanium pool of irregular shapes; (b) zoomed region of a titanium pool; (c) mapping of tungsten in red and titanium in green within the zoomed region in (b) [28]. Adapted with permission from Aguirre et al. [28]. Copyright 2009 Springer Nature.

Wurster et al. [56] investigated the fracture toughness of different tungsten-tantalum alloys (up to $10 \mathrm{wt} \%$ tantalum) and found comparable values to those of CPW, which suggested that tantalum addition has a limited influence on performance. Reith et al. [57] concluded that neither tantalum nor vanadium improves the DBTT or the Charpy impact energy in the temperature range from 700 to $1100{ }^{\circ} \mathrm{C}$ (Figure 8). The main conclusion from these analyses is that there is currently no definite evidence on the effectiveness of these alternative alloying elements, with some studies even showing detrimental outcomes.

Ultrafine-grained or nanocrystalline microstructures of tungsten can provide both high strength and improved ductility [42]. This structure can be achieved through topdown or bottom-up approaches. In the former, grain refinement is achieved through fabrication routes, such as rolling, extrusion, and other severe plastic deformation techniques. The bottom-up approach involves compacting and sintering nanosized tungsten 
powder; however, to date, there has been no evidence of improving ductility through this approach [33]. In contrast, the top-down approach has widely shown to improve ductility. For example, Faleschini et al. [29] showed that an ultrafine-grained microstructure can significantly decrease brittleness at room temperature in fracture toughness tests. In this study, high-pressure torsion was used as a severe plastic deformation method to produce a microstructure with grain sizes of approximately $300 \mathrm{~nm}$. Estimates of the DBTT were subsequently obtained for the sintered and worked materials, with the sintered material having a DBTT of approximately $400{ }^{\circ} \mathrm{C}$ and the worked material having values which ranged from 80 to $200{ }^{\circ} \mathrm{C}$. The production of an ultrafine-grained structure through this top-down approach is similar to the thermomechanical processing method described earlier as both involve the application of severe deformation techniques. In general, large amounts of plasticity in tungsten arise as a consequence of refinements in grain structure which results in an improvement in ductility. This has been supported by most studies within the literature.

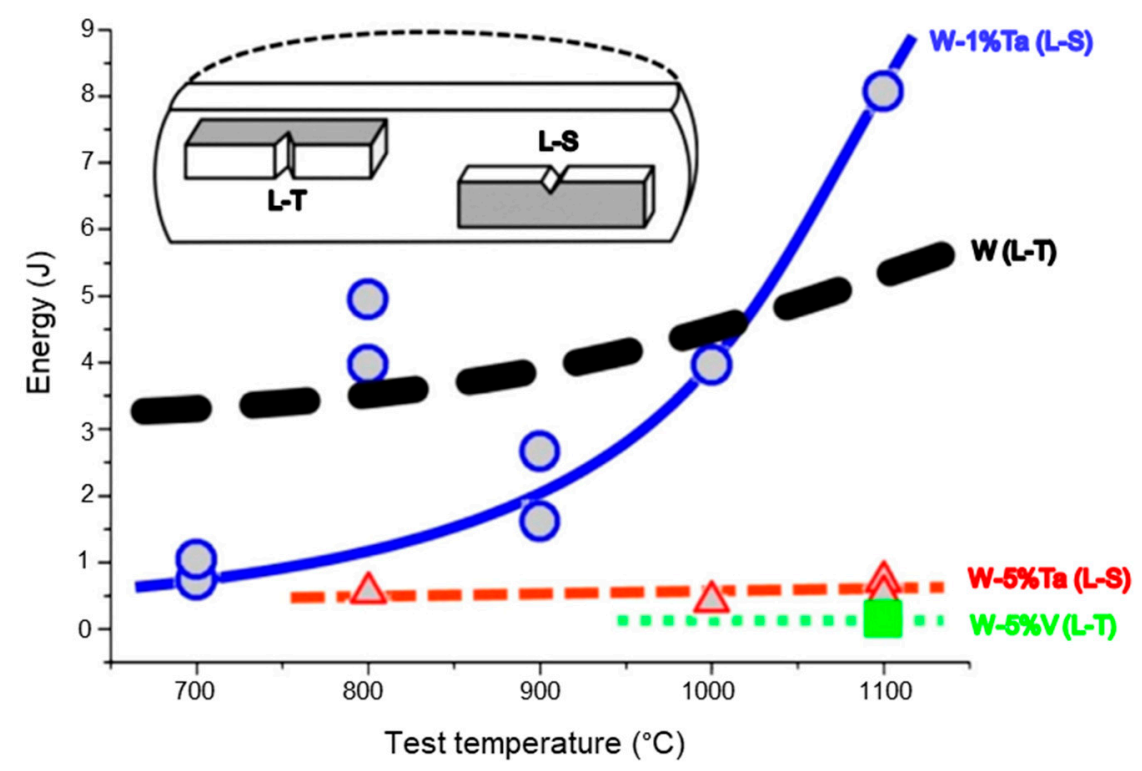

Figure 8. Charpy test results of CPW, tungsten-tantalum, and tungsten-vanadium alloys with chosen L-T and L-S orientations indicated [57]. Adapted with permission from Reith et al. [57]. Copyright 2012 Taylor \& Francis.

\section{Powder Metallurgy for Tungsten Production}

Due to its high melting temperature, $\mathrm{CPW}$ components are usually processed via powder metallurgy rather than casting, extrusion, or other methods $[14,58]$. The powder metallurgy process, depicted in Figure 9, includes powder production, blending, compacting, sintering, and forming. Other processing techniques, which are variants of conventional powder metallurgy, include powder injection molding (PIM), high-energy ball milling, microwave, and spark plasma sintering. PIM is a combination of powder metallurgy and plastic injection molding technologies which offers the benefits of fabricating precise, reproducible, dense, and complex-shaped parts. It involves the mixing of an organic binder with the metal powder to create a feedstock which can be molded into the desired shape before subsequent debinding and sintering [59]. PIM has been investigated as a potential time and cost-effective process with industrial level scalability. This has been the focus of extensive research by Blagoeva et al. [60], Piotter et al. [61], Zeep et al. [62], and Antusch et al. [63]. Homogenously mixed metallic powders can be mechanically alloyed in a ball mill under high energy until steady state is reached. During this process, the powder particles are repeatedly flattened, cold-welded, fractured, and rewelded after which they are compacted and sintered [64]. Microwave and spark plasma sintering are both unique methods of sintering pressed powder compacts. The former 
involves the direct and rapid volumetric heating of compacts using microwave energy [65], while the latter requires the simultaneous application of a pulse DC current and mechanical pressure to achieve high densification [66]. Both sintering methods have been developed as alternatives to the conventional furnace heating procedure to achieve enhanced mechanical and physical properties.

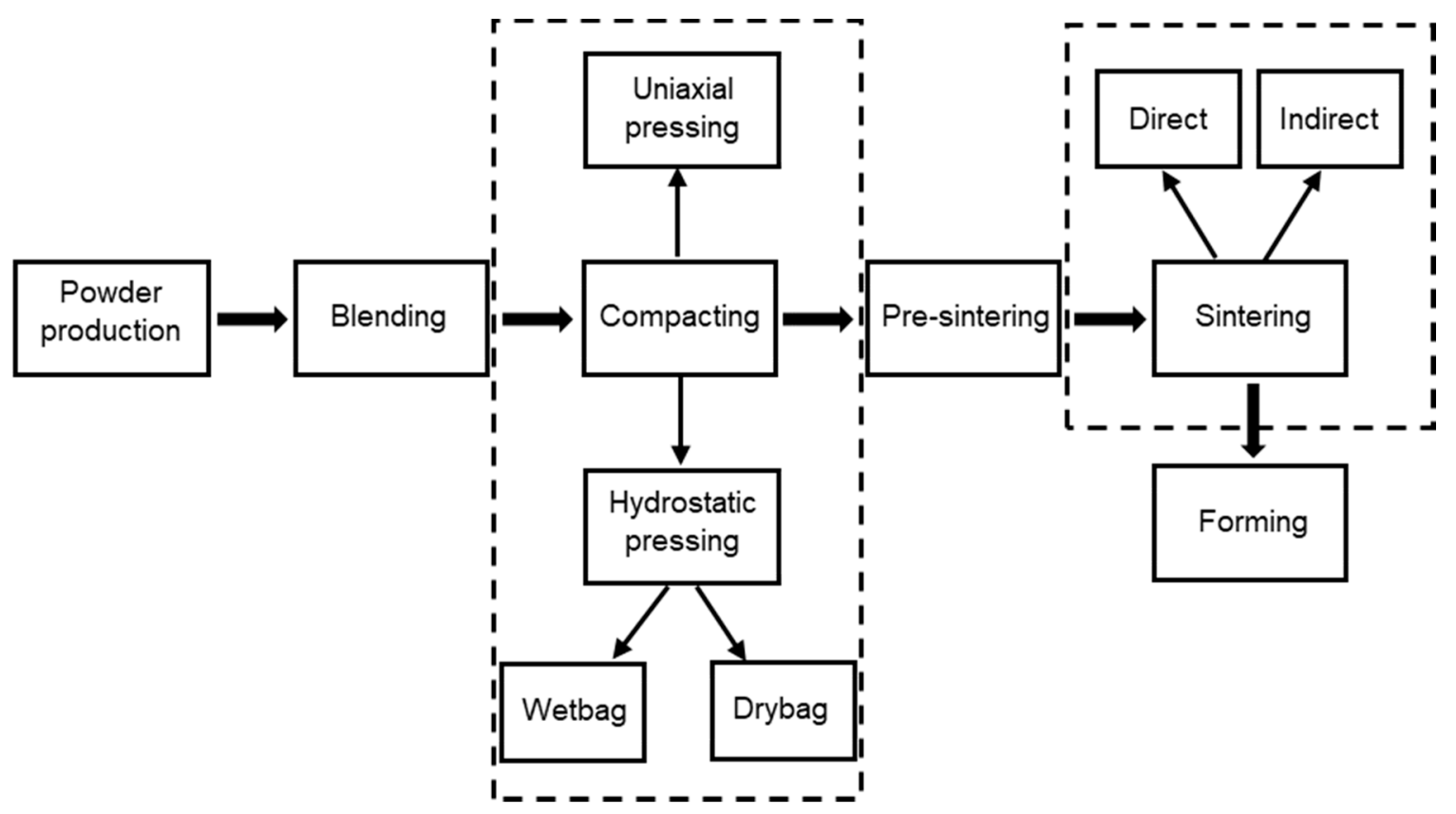

Figure 9. Powder metallurgy process diagram for tungsten.

Metal powder production is an important step in powder metallurgy as the powder characteristics have a significant impact on the outcomes of subsequent processes and the overall properties of the processed metal. In particular, the amount of entrapped impurities has a direct effect on the workability of the final product $[10,61,62]$. Therefore, a high level of powder purity is required in tungsten powders, particularly given that further purification by evaporation during sintering is limited. CPW powder is usually produced by hydrogen reduction of high-purity tungsten oxides, including tungsten trioxide $\left(\mathrm{WO}_{3}\right)$, tungsten blue oxide $\left(\mathrm{WO}_{3-\mathrm{x}}\right)$, and, in some cases, tungstic acid $\left(\mathrm{H}_{2} \mathrm{WO}_{4}\right)$. The reduction process is carefully controlled and is performed in a push-type or rotary furnace with several temperature zones maintained between 600 and $1100{ }^{\circ} \mathrm{C}$ [10].

Blending involves the mixing of powders of other alloying elements, typically with low melting temperatures, with tungsten powder in predetermined proportions. Alloying elements which are commonly used include rhenium, tantalum, and molybdenum [14]. Other less frequently used alloying elements include nickel, iron, copper, cobalt, and chromium. Alloying with nickel and iron or nickel and copper results in a popular class of alloys called tungsten heavy alloys (WHAs). In these alloys, Ni:Fe ratios of 7:3 or 8:2 [67] and Ni:Cu ratio ranging from 3.2 to 4.1 [68] are typical.

Compacting can be achieved via either uniaxial pressing in rigid dies or hydrostatic pressing in flexible molds. Although the high hardness and strength of the tungsten powder makes compacting difficult, the process is usually carried out without lubrication to avoid the introduction of contaminants which affect the properties of the final product. The output of this stage is a sufficiently strong and dense product that is commonly referred to as a green compact [10].

Sintering is a heat treatment process in which the densification of the green compact is increased to about $92-98 \%$ of the theoretical density. This process is usually carried out at high temperatures ranging from 2000 to $3050{ }^{\circ} \mathrm{C}$ and under a high-purity dry hydrogen reducing atmosphere which is used to remove or reduce the oxygen coating present on 
particle surfaces. The two methods used to accomplish this are direct and indirect sintering which mainly differ in the heating mechanism used [10]. Before the actual sintering, and to aid the material handling during this process, the green compact is first put through a presintering stage to increase the strength. Pre-sintering is usually performed in a hydrogen atmosphere at temperatures between 1100 and $1300{ }^{\circ} \mathrm{C}$ [14].

The final process is forming, which involves the plastic deformation of tungsten, and is a challenging process that typically requires significant experience to successfully implement. To achieve the desired tolerances, geometries, and properties of the final parts, a multistage hot or cold forming process is used. Common forming techniques for CPW include (i) rolling (for rods and sheets), (ii) forging (for large parts), (iii) swaging (for rods), and (iv) drawing (for wires and tubes) [10]. Unlike in other metals, hot forming of CPW in the as-sintered condition is usually performed at temperatures below recrystallisation to avoid embrittlement due to grain growth and coarsening [69]. As the process proceeds, the temperature is reduced gradually as the aim is to maintain it below the recrystallisation temperature, which decreases as deformation continues [10]. These workability challenges set limitations on the complexity of geometries which can be produced

\section{Additive Manufacturing of Tungsten}

Additive manufacturing techniques have recently been considered as an alternative technological route for producing CPW parts to meet specific geometric and property requirements. Techniques which have been used include wire arc additive manufacturing (WAAM) and laser additive manufacturing (LAM). These techniques allow layer-by-layer deposition of three-dimensional structures with the added advantage of producing complex near net-shaped components. A schematic of a typical set-up used for deposition via WAAM is shown in Figure 10 [70].

WAAM was used to deposit large scale unalloyed CPW structures by Marinelli et al. [70,71]. The authors concluded that WAAM can produce components with structural integrities sufficient for the nuclear sector. Marinelli et al. [71] acknowledged the occurrence of structural defects, including pores and micro-cracks during deposition. However, this effect is highly dependent upon the orientation of the wire feeding. Front wire feeding performed better in this study as opposed to side wire feeding as it resulted in the formation of a defect-free structure. In addition, the microstructure of the deposit formed using front wire feeding is symmetric and has a regular grain distribution. The authors argued that this process and method of wire feeding could be considered a strong alternative to powder metallurgical production of CPW in regard to its ability to produce fully dense large-scale components for the fusion industry. Aside from the absence of observable defects, the authors did not consider how the properties of the as-deposited structures compare with CPW produced via other routes. This is enough reason to question any assertion on the suitability for fusion applications. In this regard, consideration of the material properties of WAAM tungsten was the subject of a later study by the same authors in which the thermal expansion, thermal diffusivity, density, specific heat capacity, and thermal conductivity were determined as functions of temperature, and were then compared to other processing routes [70]. It was noted that the variation of the thermal conductivity of the as-deposited samples agrees with measurements made elsewhere, on components produced via methods such as chemical vapor deposition (CVD) [72] and vacuum plasma spraying (VPS) [73]. Furthermore, the thermal conductivity of the as-deposited component was higher. This was attributed to the superior purity, higher density, and lower number of grain boundaries in WAAM structures.

Selective laser melting (SLM) has been widely used for fabricating metal parts made from titanium alloys, stainless steel, CoCrMo alloys, and copper alloys. A schematic of the process is shown in Figure 11. However, this technique is difficult to apply to tungsten or its alloys. This is primarily due to the high melting temperature, thermal conductivity, and oxidation tendency of tungsten [74]. The process is widely agreed to result in the formation of cracks and porosity within the processed parts. Braun et al. [75] investigated 
the impact of impurities, process atmosphere, and substrate plate temperature on the properties of the processed material, including the formation of microstructural defects in the form of cracks and residual porosity. These defects were found to be caused by the segregation of oxygen impurities to the grain boundaries and the associated weakening of these boundaries. According to Iveković et al. [76], SLM of CPW and tungsten-tantalum alloys also resulted in the formation of cracks due to the presence of thermal stresses during solidification. Nie et al. [77] performed a comparative study involving femtosecond fiber lasers with 80 and $1 \mathrm{MHz}$ frequency and continuous wave laser. Their study demonstrated that only the $1 \mathrm{MHz}$ laser was successful in producing a solid tungsten cube. However, the characterization of this part revealed discontinuities and pores within the grain structure. The authors also showed that the ultimate tensile strength and hardness of this part were significantly reduced when compared to those of conventionally sintered parts. As a result, at present, these microstructural defects limit tungsten SLM parts to non-structural applications. This conclusion of non-structural use of SLM components is supported by many studies including those by Zhou et al. [78] and Wang et al. [74].

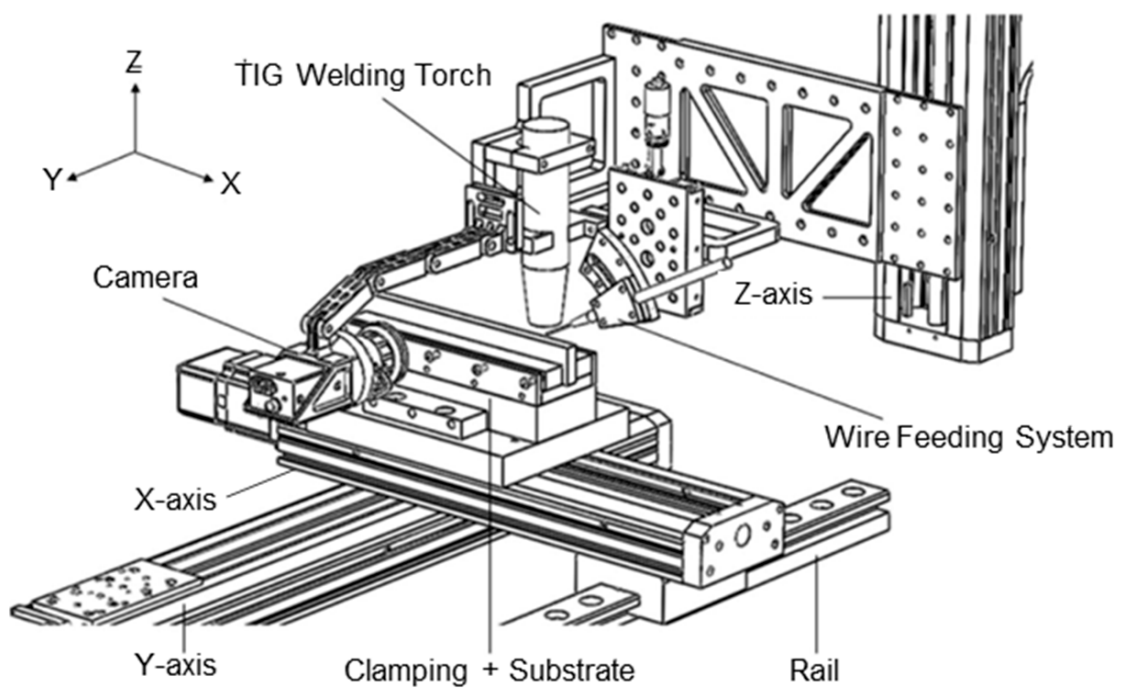

Figure 10. Schematic of the wire arc additive manufacturing system [70]. Adapted with permission from Marinelli et al. [70]. Copyright 2019 Elsevier.

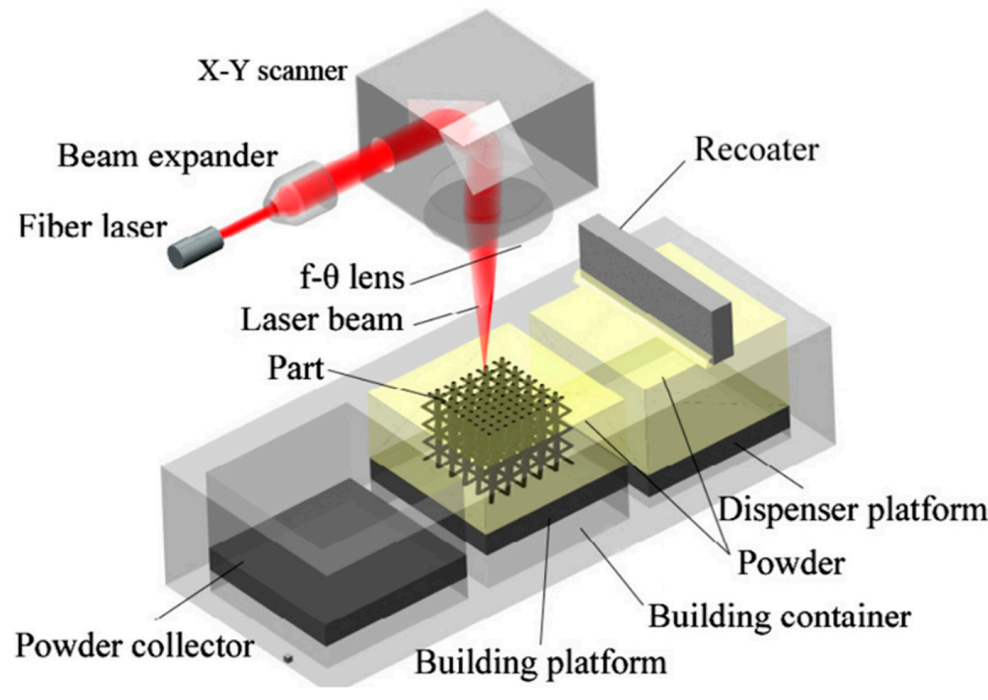

Figure 11. Schematic of the selective laser melting system [79]. Adapted with permission from Guan et al. [79]. Copyright 2013 Elsevier. 
The densities of parts produced through SLM have also been found to present issues within many studies. However, more recent analysis has indicated that this parameter can be tailored through the careful control of process parameters, laser power, and powder characteristics. For example, Wang et al. [80] showed that increasing the laser energy density increases the absolute density of the W-Ni-Cu components produced. Doubling the energy density from 12 to $24 \mathrm{~J} / \mathrm{mm}^{3}$ increased the density from 9.2 to $10 \mathrm{~g} / \mathrm{cm}^{3}$. However, this study also showed that this increase in density is limited beyond $24 \mathrm{~J} / \mathrm{mm}^{3}$ due to the difficulty of melting tungsten particles even at high energy density. Similarly, Wang et al. [81] investigated the influence of various factors including the laser power, scanning speed, laser trace width, and the number of scanning passes on the densification of W-Ni-Fe alloy. The laser power and scanning speed were found to be the most significant parameters affecting density. Increasing the power and decreasing the scanning speed improved densification. A relative density of up to $94.7 \%$ was achieved with a variation in the specific energy input level, as shown in Figure 12. Figure 12 also shows the relative density appearing to plateau with an increase in the power input. This observation aligns well with findings by Wang et al. [80] where the influence of laser power on densification diminishes at high values.

In contrast to the above, studies concerning tungsten powder characteristics have largely centered around the effect of spheroidization on densification. These studies agree that spherical powders, with inherently higher packing density, can increase laser absorptivity, enhance the formation of continuous molten tracks, and increase densification. Field et al. [82] proved this effect by showing that plasma-spheroidized powder specimens have higher densities than samples produced from chemically reduced powder. This conclusion was supported by Wang et al. [74] who found that spherical powders promoted densification compared with raw polyhedral powders. In this work, a relative density of up to $96 \%$ was achieved for the CPW part. According to the authors, this increase in densification can be attributed to the formation of a continuous molten track which eliminates the problematic balling phenomena.

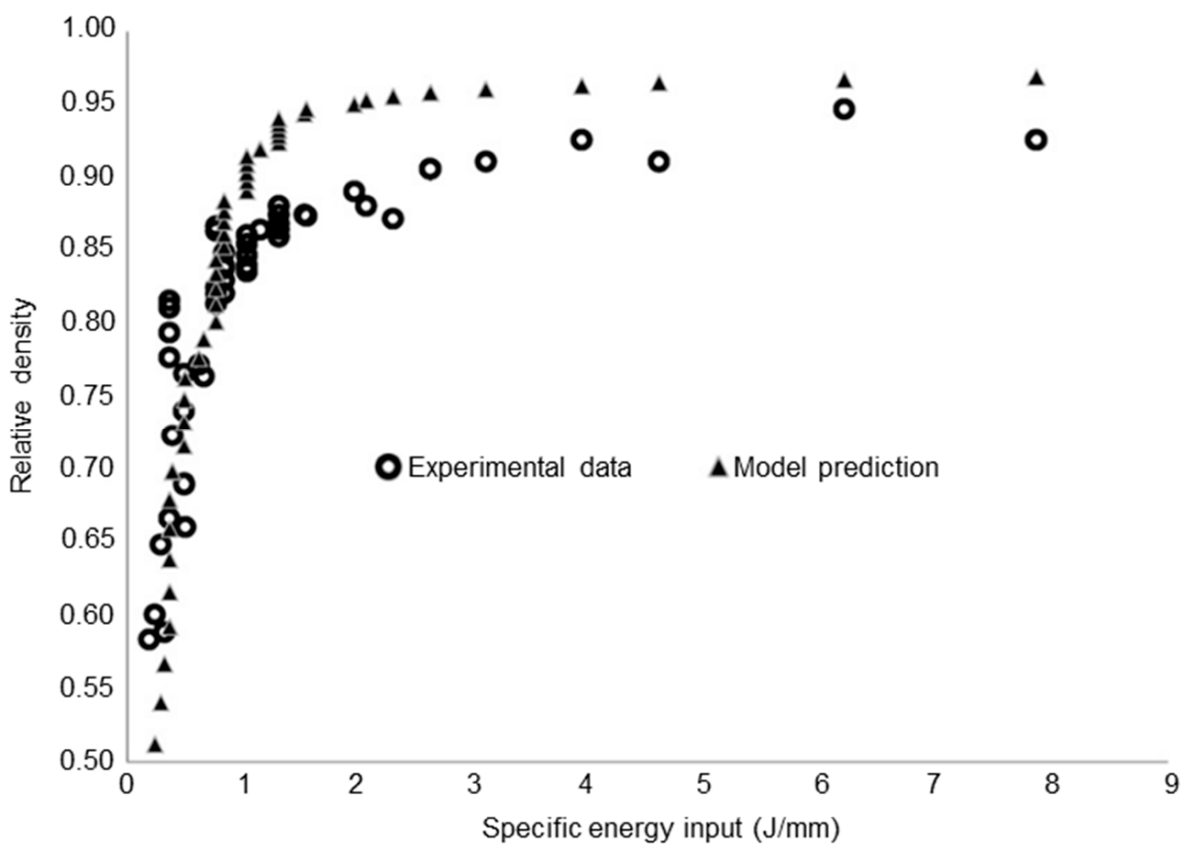

Figure 12. Variation of specific laser energy input and comparison with model prediction based on continuum modelling theory [81]. Adapted with permission from Wang et al. [81]. Copyright 2016 Elsevier.

Many studies have indicated that the melting of tungsten and the formation of balls of the melted droplets at laser focal points and entrapped cavities hinder the preparation of 
fully dense parts. This phenomenon, known as balling, can have a significantly negative effect on the parts produced from SLM. Zhang et al. [83] produced a CPW part with relative density of $82 \%$ at a scanning speed of $25 \mathrm{~mm} / \mathrm{s}$. The authors highlighted the importance of achieving a continuous molten track for promoting densification and minimizing balling. The reduced scanning speed prolonged the dwell time of the input energy and caused the formation of the required molten track. In addition, the porosity was reduced at this low scanning speed to improve part density. In another study involving a remelting procedure, Zhou et al. [78] produced bulk tungsten to study the balling effect. On their first scan, melted tungsten droplets quickly solidified to form a globular geometry (the so-called balling) rather than a flat, spread-out layer. The result was a structure with a density of up to $15.2 \mathrm{~g} / \mathrm{cm}^{3}$ with an open irregular porosity and poor surface roughness. The remelting process involved a second scan to melt the globular droplets at the building surface. This reduced the porosity and further increased the density to $16 \mathrm{~g} / \mathrm{cm}^{3}(82.9 \%$ relative density). Overall, based on the studies so far, it would appear that densification can be improved by overcoming the balling effect through either spheroidization of the powder or optimization of laser parameters, such as laser power and scanning speed.

These investigations have shown there is merit in additive manufacturing of CPW and tungsten alloys. While powder metallurgy can produce dense parts, it is limited by the complexity of geometries it can produce. Additive manufacturing, on the other hand, can produce more intricate geometries. However, there are lingering issues concerning impurities, defects, and the properties of produced parts, particularly densification. Specifically, oxidation of the tungsten powder during SLM has been identified as a source of impurities. The successful production of oxide-free CPW with WAAM has been reported, as the process is usually conducted in an ambient environment under a flow of argon shielding gas. However, it is still possible that oxygen impurities were entrapped in large WAAM parts and remained undetected. Unlike SLM, electron beam additive manufacturing is performed in a vacuum environment, which will likely reduce the possibility of oxygen ingress [84].

\section{Coating Technologies for Tungsten Thin Films}

A range of coating technologies have been developed for producing thin tungsten films, which include chemical vapor deposition (CVD), plasma spraying, and physical vapor deposition (PVD). These techniques have been the subject of investigations by the fusion industry who have an interest in growing thin tungsten layers to withstand the considerable heat flux loads. The thermal properties of the grown layer, especially the conductivity, are very crucial in these applications as they control the thermal gradient and the surface temperature of the components during operation [85]. High-purity thin tungsten layers are also required in microelectronic devices where they offer good thermal and electrical conductivity. For example, tungsten is the preferred material for gate electrodes, interconnects and barrier metals due to its high resistance to electron migration, hightemperature stability, and tendency to form stable silicides [10].

The CVD of tungsten (CVD-W) involves the high-temperature chemical reduction of an easily evaporable tungsten compound and on a suitable substrate. Often, tungsten halides, including tungsten hexafluoride $\left(\mathrm{WF}_{6}\right)$ and tungsten hexachloride $\left(\mathrm{WCl}_{6}\right)$, are used for this application while hydrogen serves as the reducing gas [10]. CVD-W has proven capable of producing layers with exceptional thermal fatigue resistance (of up to $20 \mathrm{MW} / \mathrm{m}^{2}$ ) [86] and good thermal shock resistance (of up to $2 \mathrm{GW} / \mathrm{m}^{2}$ ) [87], particularly when the material is preheated above the DBTT. The main issues with the widespread adoption of CVD-W include the relatively low deposition rate and high cost [88]. Corrosion problems may also result from the presence of chlorine and hydrogen chloride during the reduction of $\mathrm{WCl}_{6}$.

The high-temperature requirement in CVD-W can be eliminated using PVD of tungsten (PVD-W) where the substrate remains fairly cold. PVD-W is a sputtering process where an ion beam (typically of a noble gas) is generated in a high vacuum chamber by discharge. 
This high impact energy beam is focused on a water-cooled sputter target where tungsten particles are freed and deposited on a substrate. Sputter targets can include CPW, tungstentitanium, and $\mathrm{WSi}_{\mathrm{x}}$ [10]. Similar to CVD-W, PVD-W is a slow process which has a high cost.

In plasma spraying, tungsten powder is sprayed on a base material under an argon or argon-nitrogen protective atmosphere in a closed chamber [10]. Plasma-sprayed tungsten (PS-W) is preferred as an economical alternative for lower heat flux regions $\left(5 \mathrm{MW} / \mathrm{m}^{2}\right.$ or less). While the technology provides a high deposition rate and presents enhanced opportunities for in-situ repairs after damage, the thermophysical properties of the grown tungsten are inferior compared to CVD-W or PVD-W [88]. In general, a controlled lowpressure inert gas and vacuum atmosphere is used to prevent oxidation with the process appropriately referred to as VPS. The elimination of this oxidative environment results in more uniformly structured tungsten with less contamination [89]. This method of spraying also facilitates high deposition temperatures which can be used to produce layers with low porosity and high thermal conductivity [90].

Given that the method of growth affects microstructural features, such as the grain size, the grain orientation, and the impurity distribution, different deposition techniques can influence the thermal and mechanical properties. In general, these are distinct from those of the conventionally sintered bulk material. The thermal properties of the CVD-grown tungsten were investigated by Lv et al. [72], as shown in Figure 13. The grown material has a higher thermal conductivity but a similar coefficient of thermal expansion compared to conventionally forged tungsten. This high thermal conductivity was attributed to high purity and density and the columnar grain structures.
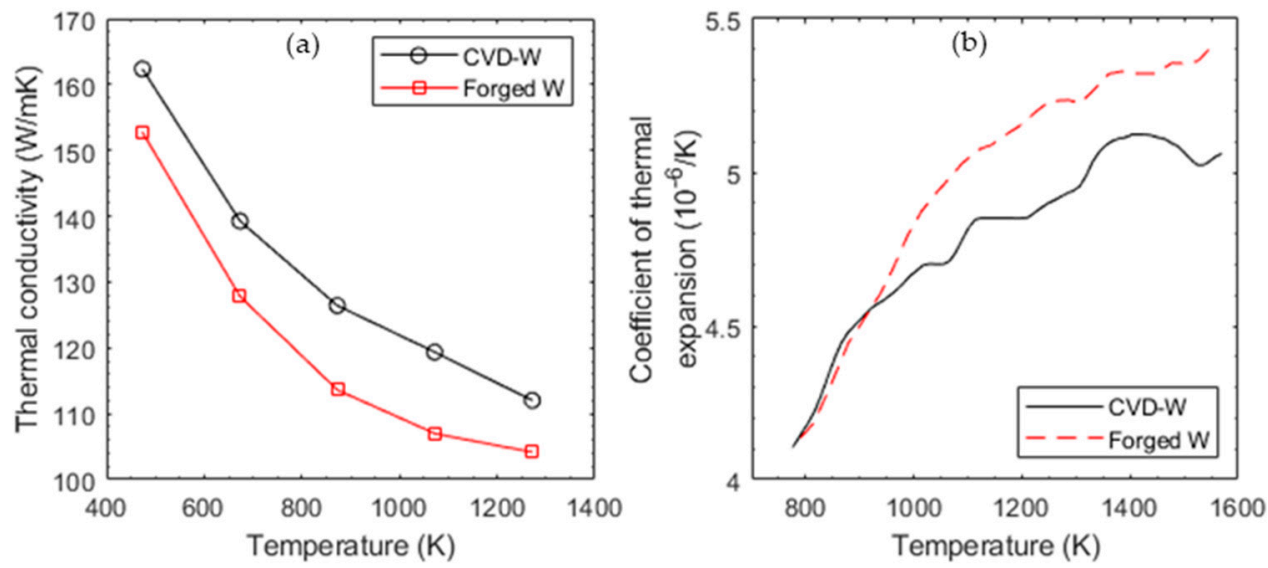

Figure 13. Thermal properties of CVD-grown tungsten and forged tungsten: (a) thermal conductivity; (b) coefficient of thermal expansion [72]. Adapted with permission from Lv et al. [72]. Copyright 2015 Elsevier.

Murphy et al. [91] studied the mechanical properties of CVD-grown tungsten at low strain rates over a temperature range of $24-967{ }^{\circ} \mathrm{C}$. The results indicate the sustained brittleness of the deposited material over this temperature range, even at strain rates as low as $10^{-6} / \mathrm{s}$. This is different for conventionally fabricated tungsten which, under similar conditions, was found to be ductile at temperatures above $120^{\circ} \mathrm{C}$ [92]. The study by Lassila and Connor [93] supports this finding that CVD-grown tungsten has a higher DBTT. Murphy et al. [91] proposed that the reason for this sustained brittleness was the segregation of fluorine to the grain boundaries as was observed experimentally.

Niu et al. [73] observed a reduced thermal conductivity and diffusivity of VPS-grown tungsten, when compared to bulk tungsten, as shown in Figure 14. The authors attributed these to the defective microstructural characteristics which include the formation of microcracks, tungsten oxide, as well as interfaces between lamellae and micropores, all of which culminate in the inferior thermal properties of the grown tungsten. 

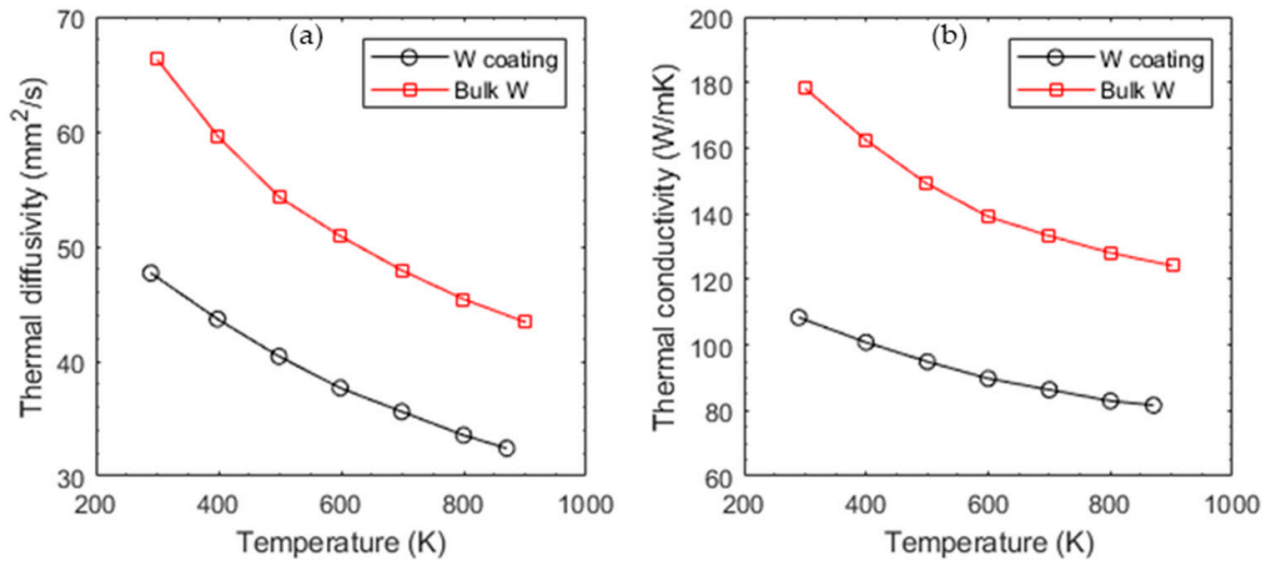

Figure 14. Thermal properties of VPS-grown tungsten compared to bulk tungsten: (a) thermal diffusivity; (b) thermal conductivity [73]. Adapted with permission from Niu et al. [73]. Copyright 2010 Elsevier.

An earlier study by Neiser et al. [85] evaluated the properties of VPS-grown tungsten by comparing their results with high-purity, well-annealed CPW. Figure 15 shows that the measured thermal conductivity of VPS-grown tungsten is approximately $60 \%$ of the bulk tungsten for temperatures ranging from 25 to $1500{ }^{\circ} \mathrm{C}$. According to the authors, this low value is due to its lower density ( $90 \%$ of theoretical density) and "splat"-type microstructure. The deposited tungsten was also observed to be anisotropic and has about $70 \%$ of the elastic modulus of the bulk material.

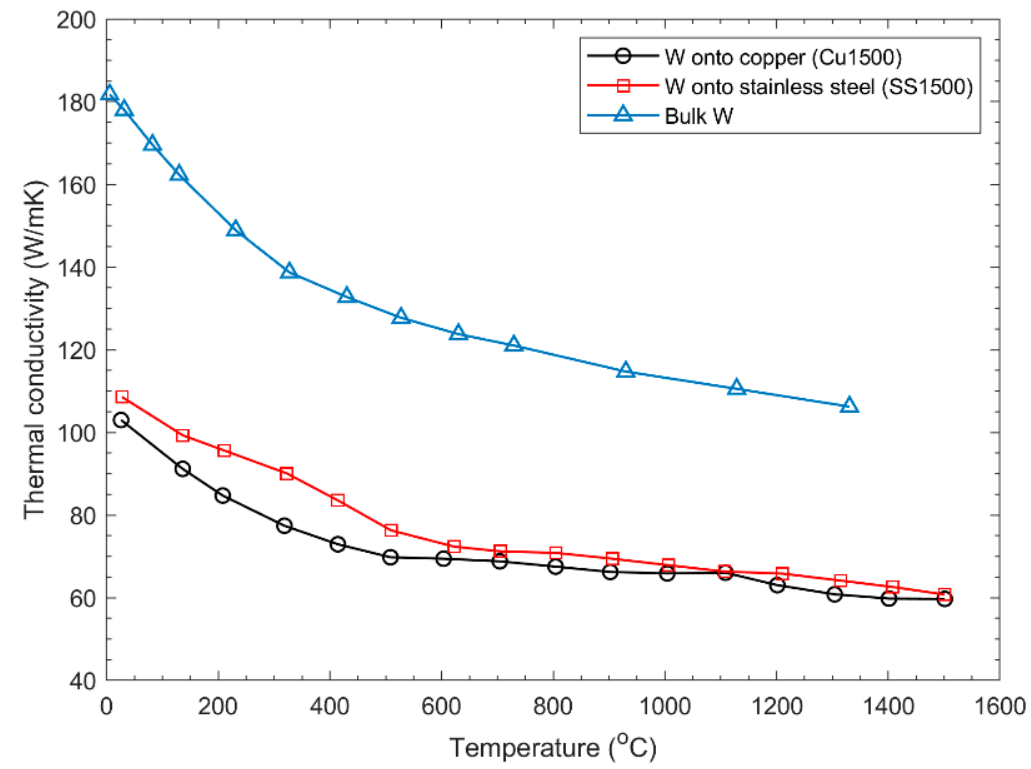

Figure 15. Variation of thermal conductivity with temperature for VPS-grown tungsten and bulk CPW [85]. Adapted with permission from Neiser et al. [85]. Copyright 1993 Springer Nature.

The capability of these technologies to produce layers with micron-level thickness has restricted their application from bulk manufacturing. However, considerable use is still found for them in areas where technically and economically viable solutions for bulk tungsten production (with limited thickness) are not found.

\section{Machining of Tungsten}

Irrespective of the initial processing technology, tungsten parts typically require a degree of machining to meet requirements in geometrical accuracy and surface properties. 
Even near-net-shaped parts fabricated by additive manufacturing and powder metallurgy require a degree of finish machining. Due to its inherent brittleness, high material strength and hardness, tungsten is considered a difficult-to-machine material. While conventional machining of CPW is practiced in industry with enormous difficulties, there is minimal academic literature available on these processes. The main problems associated with conventional machining of tungsten include their short tool life and chipping of the material [69]. For these reasons, near-net-shaped processes are used to minimize the need for machining. Since a degree of finish machining is at least required, non-conventional techniques have also been explored as potential means to overcome the challenges with conventional methods. In this section, investigations into both non-conventional and conventional machining of CPW and tungsten alloys are presented.

\subsection{Non-Conventional Machining of Tungsten}

One of the essential parts of a fusion reactor is the divertor which is situated at the bottom of the vacuum vessel to extract heat and ash produced by the reaction, and thereby minimize plasma contamination. The excessive thermal loads on these parts necessitate using tungsten and its alloys. However, to maintain stable temperatures, helium cooling of these parts is required [94]. The combination of the complex part geometry, coupled with the cooling channels required, means that complex machining technologies, including EDM and ECM, have been assessed. In particular, these approaches have been selected to produce precision and defect-free CPW surfaces to improve the heat transfer process in the divertor design [95]. These surfaces have been shown to be essential through high heat flux tests of divertor mockups, which revealed that defect-free tungsten surfaces are required to avoid early material or structural failures [96]. Therefore, the ability of these production processes to produce high-quality surfaces is essential. The non-contact nature of both methods, being a prime characteristic of non-conventional processes, offers advantages, including the elimination of mechanical stresses, chatter, and vibration problems [97,98]. However, both methods introduce additional cost and complexity compared to conventional machining methods. It is worth mentioning that other non-conventional processes have been applied to tungsten aside EDM and ECM. These processes include water jet cutting [99], laser cutting [100-102], and laser drilling [103,104]. A discussion of studies and findings from these non-conventional machining techniques is provided next.

\subsubsection{Electro Discharge Machining (EDM) of Tungsten}

EDM is the process of eroding electrically conductive materials by passing series of spatially discrete high-frequency electrical discharges or sparks between the tool (electrode) and workpiece in the presence of a dielectric fluid [105]. Material is removed regardless of hardness by melting and, partly, by vaporization [106]. While the application of EDM to tungsten has shown significant potential, the major difficulty associated with this process is that the thermal effects adversely influence the quality of the surfaces produced [107]. This effect can be the result of the high thermal conductivity of tungsten itself. Whilst tungsten satisfies the good electrical conductivity requirement for efficient EDM machining, its high thermal conductivity can pose challenges and limit material removal rate. With EDM being a thermal process, the high thermal conductivity of tungsten can result in poor surface integrity and high tool wear.

In a comparative study of EDM, laser etching, PIM, and ECM, Krauss et al. [95] observed the presence of strong surface defects in the form of microcracks and high surface roughness in EDM tungsten structures. At the same time, the authors found that ECM had the least microstructural impact. This validated an earlier evaluation study by the same authors [108] who observed similar microstructural defects in the EDM of tungsten slot arrays.

The limited studies of EDM of tungsten present within the literature have shown that even high-quality EDM parts are generally characterized by poorly machined surfaces. The surface defects usually include the formation of recast layers, microcracks and tensile 
residual stresses [109]. Careful control of the production processes can minimize these effects, and optimization of these approaches are worthy of further investigation. This can also offer added advantages to the production equipment, for example through reduced tool electrode wear.

\subsubsection{Electro Chemical Machining (ECM) of Tungsten}

Material removal in ECM is based on electrolysis which causes the anodic dissolution of the workpiece material [110,111].

The industrial application of ECM to tungsten is challenging due to its tendency to form a passivating $\mathrm{WO}_{3}$ oxide layer, which inhibits the continuous dissolution of the material and leads to defective surfaces [112]. Conventional electrolyte solutions used for the electrochemical etching of steel cannot remove this oxide layer; hence, suitable electrolytes with neither acidic nor neutral $\mathrm{pH}$ values are required. This has led to different laboratory-based studies, largely centered around investigating the behavior of the material in different electrolytic solutions to eliminate this passivation effect.

Krauss et al. [112] developed two variants of the ECM process, Mask-ECM (M-ECM) and Cathodic-ECM (C-ECM), in order to structure tungsten components through the optimization of the pulse current. M-ECM is a lithographic structuring method where an insulating mask (resin) is deposited on the anode before structuring. Dissolution is only possible in the uncoated regions with the mask being resistant to the electrolyte in its $\mathrm{pH}$ regime. C-ECM method works by copying the cathodic tool onto the workpiece with the distance between the anode and cathode being the main controlling parameter for material removal. The authors showed that these passivating layers could be removed by adjusting the $\mathrm{pH}$ of the electrolytes to produce the desired defect-free surfaces. Holstein et al. [96] developed a two-component electrolyte solution consisting of nitrate salt and ammonia, both of which perform different electrochemical functions. This processing technology allowed the variation of the $\mathrm{pH}$ to become independent from the electrolyte conductance. This led to two new ECM methods, Cathode-tool ECM (C-ECM) and Surface-ECM (S-ECM), which were developed for deep etching and surface treatment purposes, respectively.

Exposing surfaces that do not require machining to the electrolyte can result in unexpected stray corrosion which can have a substantial effect on ECM precision and can damage other regions of tungsten parts. One way to minimize this problem is by decreasing the concentration of the alkaline electrolyte and using a pulsed current, at the expense of the reduced material removal rate. However, by developing a solution composed of $\mathrm{NaClO}_{3}$ and $\mathrm{NaOH}$, Zhang et al. [113] showed that reduced stray corrosion and improved machining efficiency can be simultaneously achieved. They showed that the $\mathrm{NaClO}_{3}$ in the electrolyte increased the electrolyte's conductivity and formed an oxide film in the unmachined regions, thereby eliminating stray corrosion in these regions. In contrast the $\mathrm{NaOH}$ removes the oxide film in the machined regions and ensures the continuous dissolution of the material. Optimization of the approach revealed that $10 \mathrm{wt} \% \mathrm{NaClO}_{3}$ and $0.3 w t \% \mathrm{NaOH}$ are particularly effective concentrations for this approach.

Both EDM and ECM have also been applied to micro machining processes where complex-shaped micron-sized tungsten components are required, especially for use in micro-electro-mechanical systems. The relatively superior quality of the surfaces produced via ECM highly favors the technique for such microfabrication applications. Fan et al. [114] described the fabrication of tungsten microelectrodes using a pulsed power supply. This study also characterized the influence of various working parameters, including the applied voltage, pulsed period, duty factor, and electrolyte temperature, while showing that microelectrodes with a diameter of $100 \mu \mathrm{m}$ and lengths of $2 \mathrm{~mm}, 3 \mathrm{~mm}$, and $4 \mathrm{~mm}$ can be successfully fabricated. Liu et al. [115] demonstrated the use of wire electrochemical micro machining to produce micro-tools with complex geometries. However, a large pulse duration (150-190 ns) and high electrolyte concentration (0.9-1.0 mol/L) were required to achieve process stability. By using a relatively lower pulse duration (60 ns) and electrolyte concentration $(0.1 \mathrm{~mol} / \mathrm{L})$ to attain stability, He et al. [116] further improved the fabrication 
process by producing microstructures with enhanced precision. Multi-wire electrochemical micro machining was also introduced within this study which was found to improve the productivity of the process.

Overall, the electrolytic properties, including concentration and $\mathrm{pH}$, are crucial in ECM since these directly affect the dissolution of the tungsten workpiece. The industrial application of ECM to tungsten is still limited in respect due to formation of passivating $\mathrm{WO}_{3}$ oxide layers and stray corrosion. Furthermore, ECM is an expensive and energy intensive process and possibly has the highest energy footprint amongst all machining processes. The use of ECM is also linked to strict health and safety requirements further limiting the widespread adoption to date.

\subsubsection{Other Non-Conventional Techniques}

A survey of the available literature on non-conventional machining of tungsten revealed a collection of studies on water jet cutting, laser cutting, and laser drilling. Analysis of these methods is still in its early stages and usually involves the assessment of various process parameters on machining performance, albeit mostly limited to microscopic examination of the machined surfaces.

Water jet cutting uses a high-pressure jet of water or, in the case of abrasive water jet cutting, a mixture of water and an abrasive substance to cut through materials. Wang et al. [99] investigated the application of abrasive water jet for cutting a tungsten block of $400 \mathrm{~mm} \times 40 \mathrm{~mm} \times 20 \mathrm{~mm}$ dimensions. They studied the erosion mechanism and the influence of transverse speed and jet pressure on surface roughness. The transverse speed was found to have the greater influence on surface roughness with a reduction in the transverse speed, causing a reduction in the surface roughness. Micrographs of the sample also showed ploughing and brittle fracture as characteristics of the eroded surface. Although the authors attributed this erosion mechanism to the presence of abrasive particles, it could also be a result of the water jet pressure. It should be noted that although the jet pressure has minimal influence on the roughness, this is not a sufficient reason to exclude it from the discussion relating to the erosion mechanism.

Laser beam cutting and drilling uses a focused beam of laser for machining. The laser is absorbed by the workpiece surface and transformed into high-density thermal energy at the cutting zone. It is often advantageous to use very short light pulses in laser material processing to avoid significant dissipation of the energy through the material by thermal conduction. The use of these ultrashort pulsed lasers, including picosecond and femtosecond lasers, can produce high-quality surface finishes [117]. In order to assess the suitability of using lasers for high precision cutting of tungsten foils (90 and $110 \mu \mathrm{m}$ thick), Uebel and Bliedtner [102] examined different laser types, including fiber and solid state lasers with pulse durations ranging from picoseconds to a continuous wave with different wavelengths $(355,532$, and $1064 \mathrm{~nm})$. In this study, high-quality edges were found to be produced using picosecond lasers with short pulse durations, regardless of the wavelength. This eliminated the need for post-processing procedures.

Using a $\mathrm{CO}_{2}$ laser with nitrogen as an assist gas, Begic-Hajdarevic et al. [101] observed the influence of the laser power and cutting speed on surface roughness. Cutting speeds of 1000,1500 , and $2000 \mathrm{~mm} / \mathrm{min}$ and powers of 1500, 1750, and $2000 \mathrm{~W}$ were considered. They found that the $2000 \mathrm{~W}$ laser at a cutting speed of either 1500 or $2000 \mathrm{~mm} / \mathrm{min}$ produces a more uniform surface roughness along the length of the cut surface. This finding seems to suggest that higher cutting speeds should be used with high laser power.

The variety of input parameters involved in laser cutting has led to studies involving the development and application of models and algorithms for predicting the quality of cut. However, very few of these studies have been concentrated on tungsten. An artificial neural network approach was used by Klancnik et al. [118] to predict the kerf width and surface roughness of the cut surface of tungsten alloy, following a series of experiments involving the variation of the laser power, cutting speed, and assist gas type. While average prediction errors of $6.5 \%$ and $9.5 \%$ were reported for the kerf width and surface roughness, 
respectively, the amount of data required for reliably training these systems is a cause for concern.

\subsection{Conventional Machining of Tungsten}

Conventional machining is the most used secondary manufacturing process for producing finished parts. This process can be become very unproductive when applied to difficult-to-cut materials. The characteristics of difficult-to-cut metals are broad but usually include excessive cutting tool wear/short tool life, low material removal rates, high cutting forces, extreme heat build-up in the cutting zone, poor chip formation, and poor surface quality [119]. Some of these features are interdependent. For example, quick heat build-up in the cutting zone causes excessive tool wear and/or affects the surface quality and/or integrity. Materials which possess at least one of these characteristics are, thus, considered difficult to cut. Refractory metals and the alloys of titanium and nickel are known examples of difficult-to-cut materials.

Due to its high material strength and brittleness, tungsten is also considered a difficultto-cut material. The difficulties in machining tungsten and its alloys stem from the properties outlined in Section 2. Whilst heat accumulation at the cutting zone due to poor thermal conductivity is a major issue in machining titanium and nickel alloys, tungsten does not benefit from thermal softening at the cutting zone due to its high thermal conductivity and resulting thermal dissipation. Rapid tool wear and brittle fracture or material chipping have been reported to be characteristics of machining tungsten [69]. Properties which can affect machinability include:

1. High DBTT;

2. High hardness and strength;

3. High strain hardening tendency;

4. High shear strength;

5. Increase in recrystallisation tendency with increase in level of deformation.

The few published investigations into conventional machining of $\mathrm{CPW}$ are recent. These are mostly focused on the observation of tool performance and the underlying wear mechanisms. Zhong et al. [120] observed more severe wear on the rake face compared to the flank face of the polycrystalline diamond (PCD) tool during micro cutting of CPW $(99.95 \mathrm{wt} \%)$. Microchipping and flaking were found to dominate the wear on the cutting edges and the rake face, respectively. These were explained to be due to the cutting load, fatigue, impact by chips, and burr formation. Legutko et al. [121] found that abrasion dominated the tool wear mechanism when turning 99.7\% CPW and that chemical wear and other wear types had minimal impact. Among other tools used, including SiAlON ceramics ( $\mathrm{TiC}$ coated and uncoated), whisker-reinforced alumina ceramic tools proved to have the best machining outcomes in terms of resistance to the abrasive wear, especially at low cutting speeds $(\sim 40 \mathrm{~m} / \mathrm{min})$. The authors also reported the absence of built-up edge formation which was attributed to the brittleness of the material and the formation of splintered chips.

Olsson et al. [122] tested eleven different tool materials in a comparative study to determine which was most suitable for turning $99.95 \% \mathrm{CPW}$ with the use of high-pressure coolant. This study was performed to expand the limited knowledge base available for machining CPW. TiAlN-TiSiN PVD-coated and -cemented carbide and PCD tools gave the best results in this study, although PCD was superior, as shown in Figure 16. The wear mechanisms of both tools were also analyzed. For the carbide tool, abrasion, oxidation, and cracking of WC grains and diffusional dissolution of WC and Co were observed. In the case of the PCD tool, abrasion and diffusional dissolution were identified as the main wear mechanisms. Furthermore, the poor surface quality and sub-surface damage of the workpiece were attributed to a few distinct factors, including cracking, formation of built-up edges, residual porosity, and adhesion on the machined surface. 

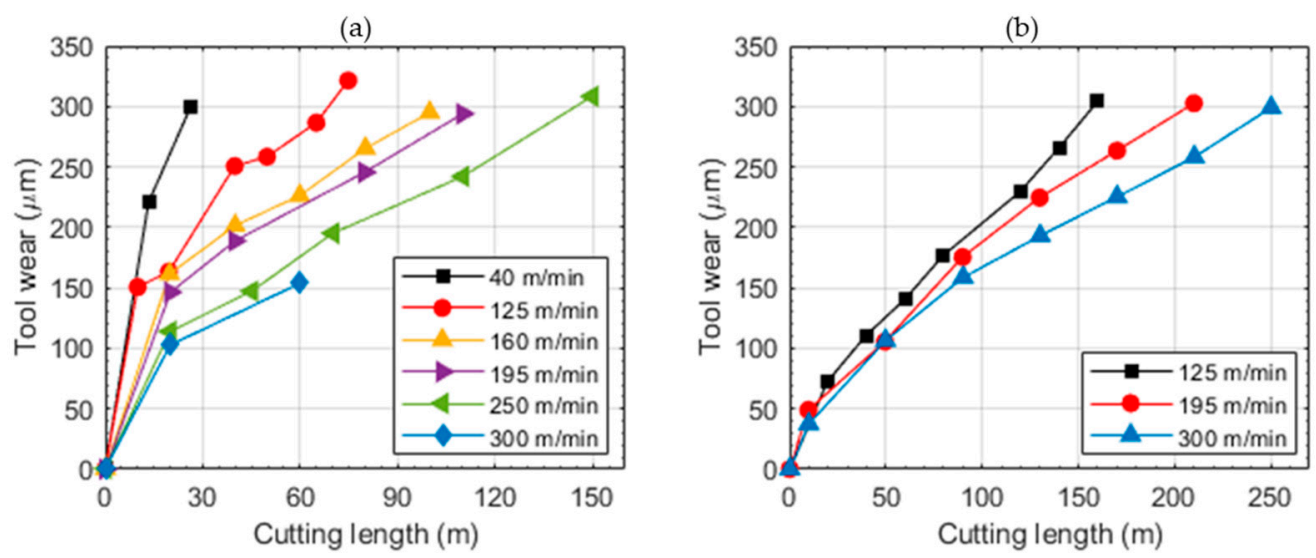

Figure 16. Flank wear measurements at different cutting speeds for (a) PVD-coated carbide; (b) PCD tools [122].

In a separate study of different machining methods, Olsson et al. [123] investigated the performance during the longitudinal turning of CPW with TiAlN-TiSiN-coated carbide tools. The methods used include cryogenic $\mathrm{LN}_{2}$ cooling; induction-assisted heating; and dry, flood, and high-pressure cooling. Results from the optimized conditions are shown in Figure 17, with cryogenic $\mathrm{LN}_{2}$ cooling improving the tool life the most, despite the significant level of adhesive wear. This improvement was explained to be a result of the slowed rate of diffusional and oxidational wear mechanisms.

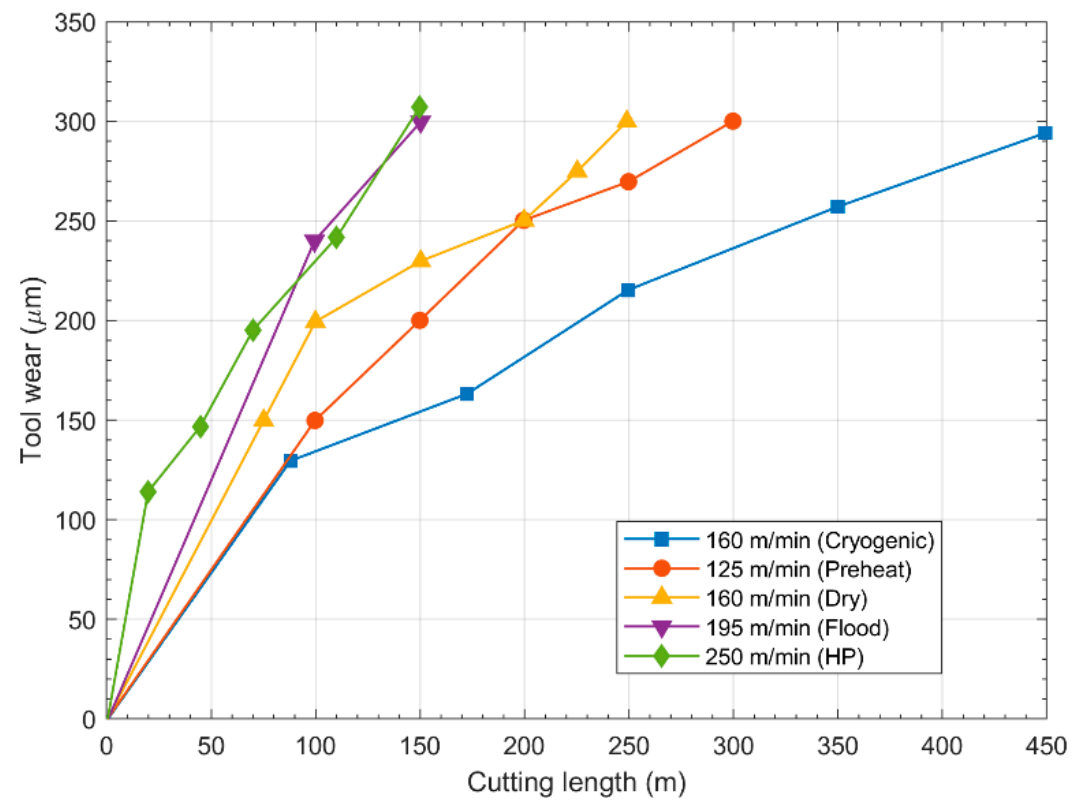

Figure 17. Tool wear measurements at optimal cutting conditions for different machining methods [123].

In terms of the effect on the cutting zone, the machining methods in Figure 17 can be conveniently classified as low-temperature (flood, high-pressure, cryogenic $\mathrm{LN}_{2}$ ) and high-temperature (dry and induction heating) processes. Except for cryogenic cooling, the results suggest that the cooling methods are inferior techniques for machining CPW. If cryogenic machining was excluded from Figure 17, the resulting plots would have been expected and backed up by a consideration of the DBTT of tungsten. Figure 17 also shows that the optimal cutting conditions for the low-temperature processes require higher cutting speeds except for cryogenic cooling. This effect can be explained as a compensation for low temperature by a high cutting speed. This is also in agreement with the high 
process temperature requirement during the machining of tungsten. However, cryogenic machining, being a low-temperature process, seems to be an anomaly in this case and tends to nullify this plausible explanation. Olsson et al. [123] argued that the superior performance of cryogenic machining was because of the absence of oxidation wear of the carbide grains due to the presence of a protective nitrogen atmosphere. While the focus of this study was on the cutting tool performance, the authors did not analyze the surface integrity after machining. It would be beneficial to consider the effects of the different machining methods, especially cryogenic cooling, on surface integrity, in addition to an observation of cutting tool performance, as presented in the study.

The limited literature on the machining of CPW led to a consideration of studies on porous tungsten. Porous tungsten is a less dense alloy that is usually sintered at lower temperatures than those described in Section 3. The material has numerous applications including as a dispenser cathode for microwave tubes, cathode ray tubes, and ion lasers [124]. Surface porosity is an important characteristic which ensures its functional and reliable use. One approach for achieving this is to infiltrate the tungsten powder with copper or plastic during the sintering process. This method has been shown to improve machinability and to achieve the desired surface quality [124]; however, the open pores formed after machining also serve as removal sites for the infiltrant. Improved machinability has been reported by Das et al. [125] through the addition of copper. Nevertheless, infiltration techniques can also have negative implications; the process can be time-consuming and can introduce contaminants into the material. This approach also raises sustainability concerns due to the handling and disposal of infiltrants [124]. These shortcomings have served as motivation for a series of studies on the application of cryogenic machining to porous tungsten.

Pusavec [124] investigated the potential of cryogenic machining to improve the machinability and enhance the material surface quality in terms of the pore size distributions. Figure 18 compares the distributions for cryogenically and conventionally machined surfaces. Despite the slightly inferior surface of the cryogenic sample, the approach is safe and does not suffer from the limitations associated with the conventional method.
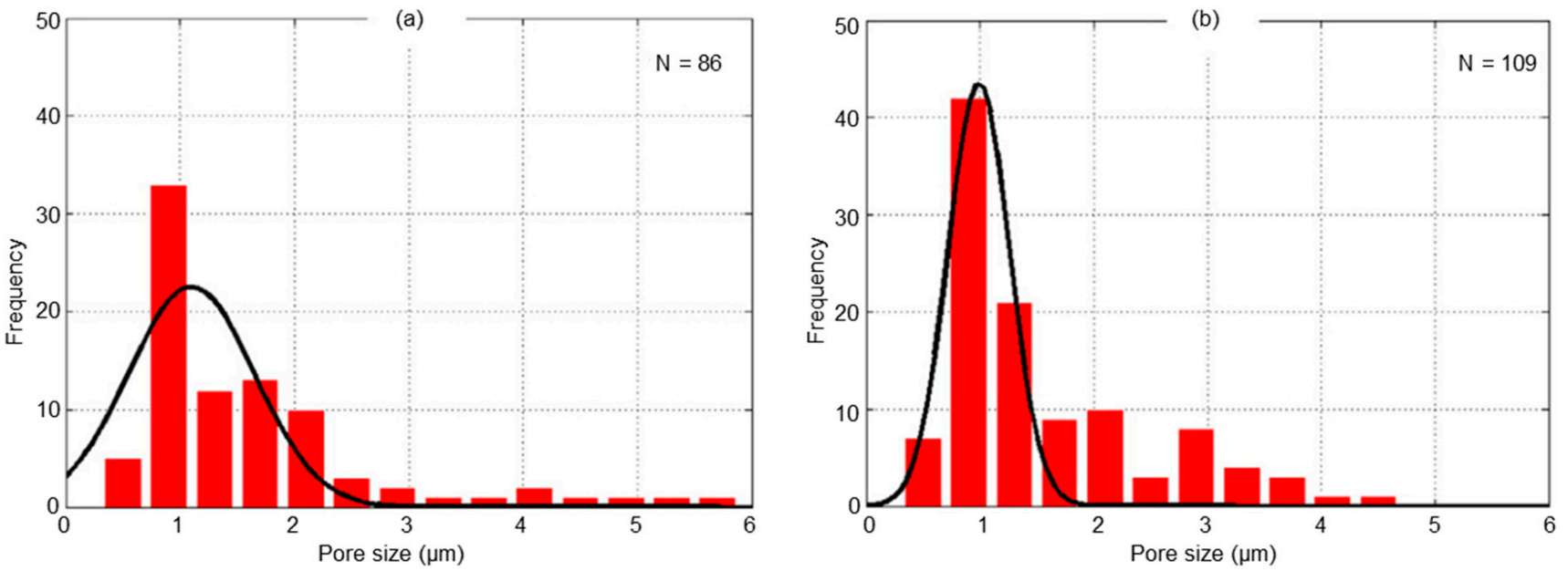

Figure 18. Pore size distribution on the machined surface: (a) cryogenic machining; (b) conventional machining with plastic infiltrant [124]. Adapted with permission from Pusavec [124]. Copyright 2012 Elsevier.

Pusavec [124] used a genetic algorithm to optimize the cutting parameters and tool grade for a specified surface quality. It determined that PCD tools gave the best performance of the tool grades considered.

An earlier study by Tarter et al. [126] also highlighted similar benefits of cryogenic machining of porous tungsten. Compared with thermal assisted machining, Nee et al. [127] found that cryogenic machining, through controlled brittle fracture, produced a far better 
surface quality in terms of the amount of porosity. This study also revealed that preheating the material is detrimental to tool life.

An in-depth study into cryogenic turning of porous tungsten was also performed by Schoop et al. [128] using PCD cutting tools. Here, the influence of various cutting parameters and cooling conditions were investigated to understand the impact on the machined surface. Figure 19a shows the effects of rake angle and cooling temperature on the surface roughness and porosity. The more negative the rake angle the higher the surface roughness regardless of the pre-cooling temperature. The porosity level and surface roughness were also greater at the lower temperature regardless of the rake angle. This effect, attributed to brittle fracture, is due to the lack of ductility of the metal at low temperatures.

(a)
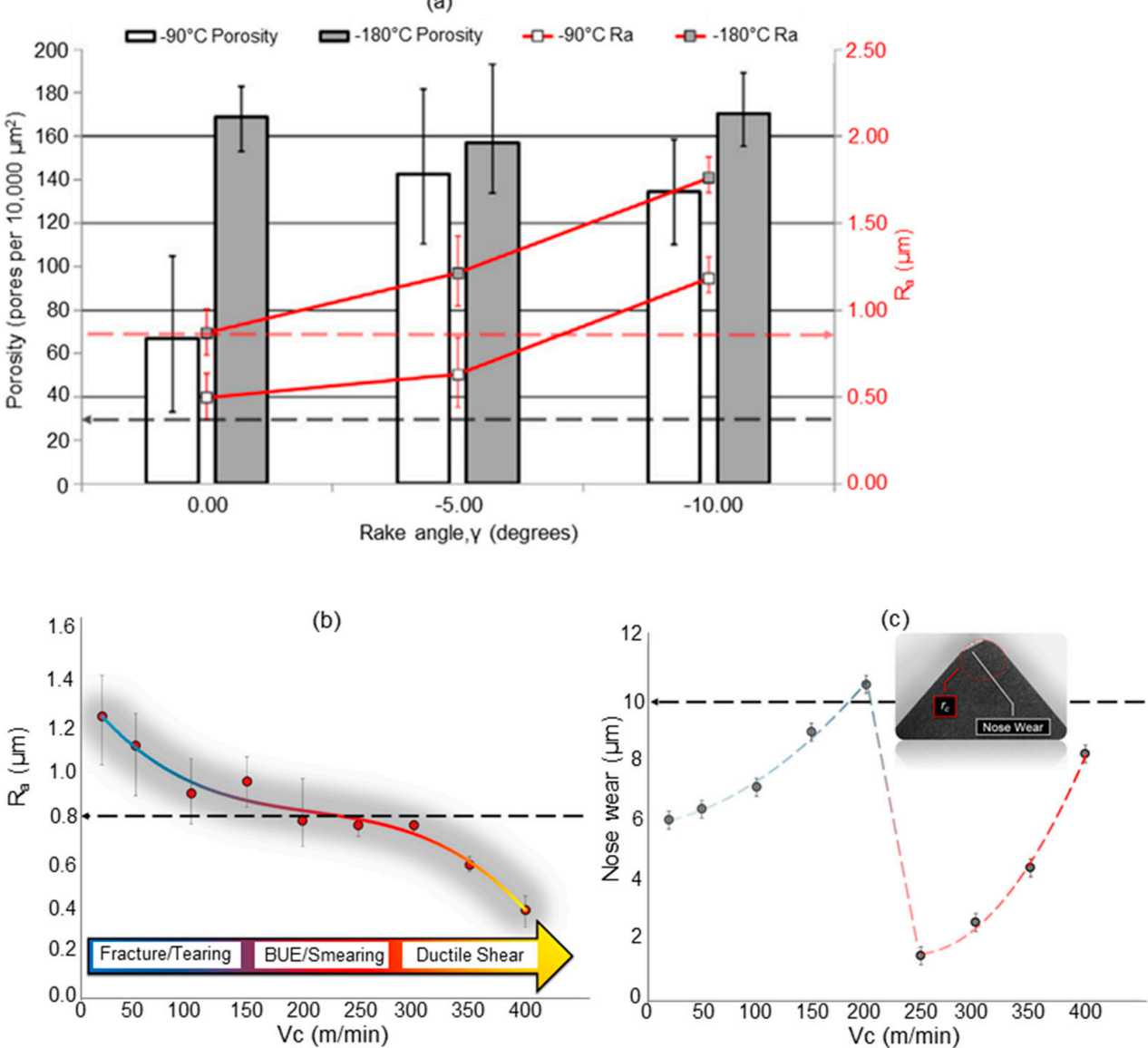

Figure 19. (a) Dependence of the porosity and surface roughness of cryogenically machined porous tungsten on the rake angle for two pre-cooling temperatures; (b) influence of the cutting speed on the surface roughness at a pre-cooling temperature of $-180^{\circ} \mathrm{C} ;(\mathrm{c})$ effect of the cutting speed on tool wear at $-180^{\circ} \mathrm{C}$ [128]. Adapted with permission from Schoop et al. [128]. Copyright 2016 Elsevier.

The influence of the cutting speed on the surface roughness was also investigated in three regimes, as shown in Figure 19b. It was found that the surface roughness reduces with increasing the cutting speed. The abrupt reduction of the roughness at speeds beyond $300 \mathrm{~m} / \mathrm{min}$ led the authors to hypothesize that the DBTT was exceeded in those regions.

Tool nose wear observations corresponding to Figure $19 \mathrm{~b}$ were also made by Schoop et al. [128], as shown in Figure 19c, in which the effect of cutting speed was shown to be not monotonous. At speeds up to $200 \mathrm{~m} / \mathrm{min}$, the rapid tool wear was attributed to attrition due to the formation of an unstable built-up edge (BUE) and the competition between brittle and ductile modes of deformation. The reduction in tool wear, equivalent to the transition in Figure 19b, is characteristic of smearing. Finally, increased thermal stress 
was credited as the reason for the further increase in wear. This study demonstrated that the surface quality of porous tungsten can be controlled by careful consideration of machining parameters, including the cutting speed, rake angle, and pre-cooling temperature.

Schoop et al. [129] also observed the effects of pre-cooling and depth of cut on surface porosity, as shown in Figure 20. They found that an increased precooling time enhanced the surface porosity and caused a more uniform porosity profile. Figure 20 also shows the drastic decrease in porosity levels at higher depths of cut (for the 60 and $120 \mathrm{~s}$ pre-cooling). This trend is believed to be associated with the transition from brittle to ductile deformation as the cutting temperature increased at larger depths of cut.

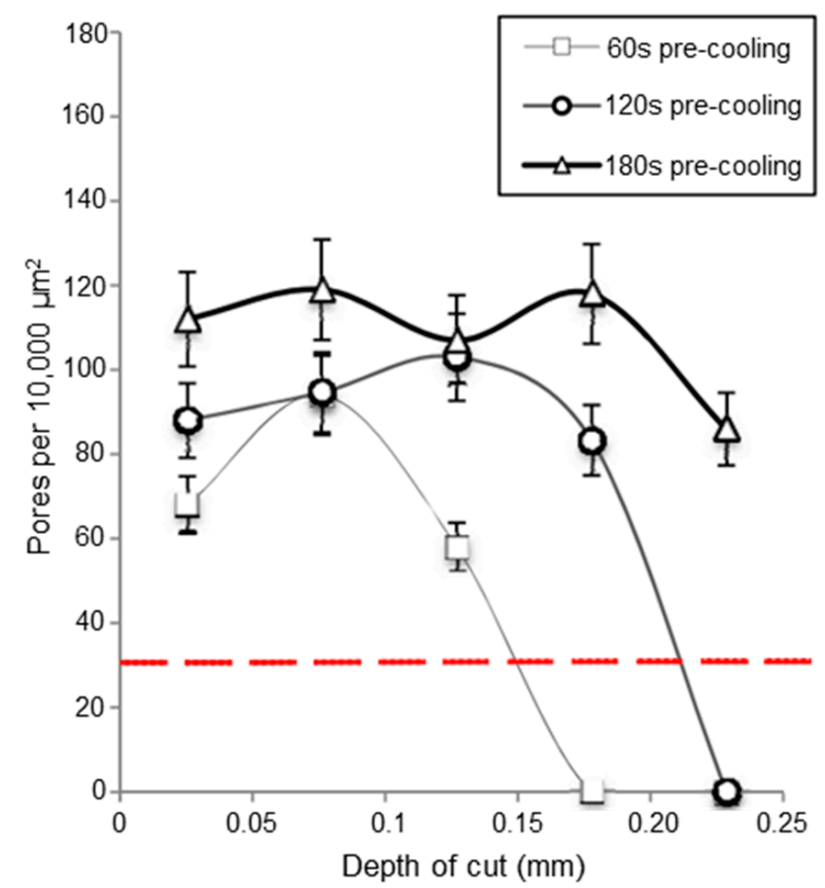

Figure 20. Effects of pre-cooling and depth of cut on surface porosity [129]. Adapted with permission from Schoop et al. [129]. Copyright 2013 Elsevier.

Schoop et al. [130] also investigated the effects of cryogenic pre-cooling and depth of cut on surface porosity. The result, shown in Figure 21a, bears strong similarities with Figure 20.

Figure $21 \mathrm{~b}$ shows that the maximum pre-cooling time results in the maximum surface roughness. The trend is consistent with that of the surface porosity. This relationship between surface roughness, porosity, and pre-cooling agrees with Figure 21a which, together, summarize the effect of cryogenic machining of porous tungsten. Figure $21 \mathrm{c}$ also shows that nose wear is significantly affected by pre-cooling. Compared to dry machining, cryogenic machining was found to reduce nose wear by approximately $50 \%$. To further observe the effect of cutting speed, Figure 22a,b show that the three lowest cutting speeds produced the highest porosity level, which was well above the typical minimum requirements. While the surface roughness did not vary much with cutting speed, nose wear was largely affected by cutting speed.

The analysis of the literature on the machining of CPW shows that studies have mostly focused on understanding the tool wear mechanisms with limited consideration of the surface quality, e.g., surface roughness, surface anomalies (microcracks, smearing, ploughing), and the subsurface microstructure. Furthermore, there is not enough emphasis on machining from an understanding of the material's brittleness and enhancement of its ductility. For porous tungsten, cryogenic machining has proven to be a worthy replacement of the more conventional and unsustainable infiltrant method of machining. While considering various machining parameters, the process of controlled brittle fracture machining 
can produce surfaces fit for use as dispenser cathodes. The aims of these studies on the machining of porous tungsten were to maintain surface porosity and prevent filling of the pores by plastic deformation. This is contrary to the overall aim of economic machining of fully dense CPW for high-quality components.

(a)

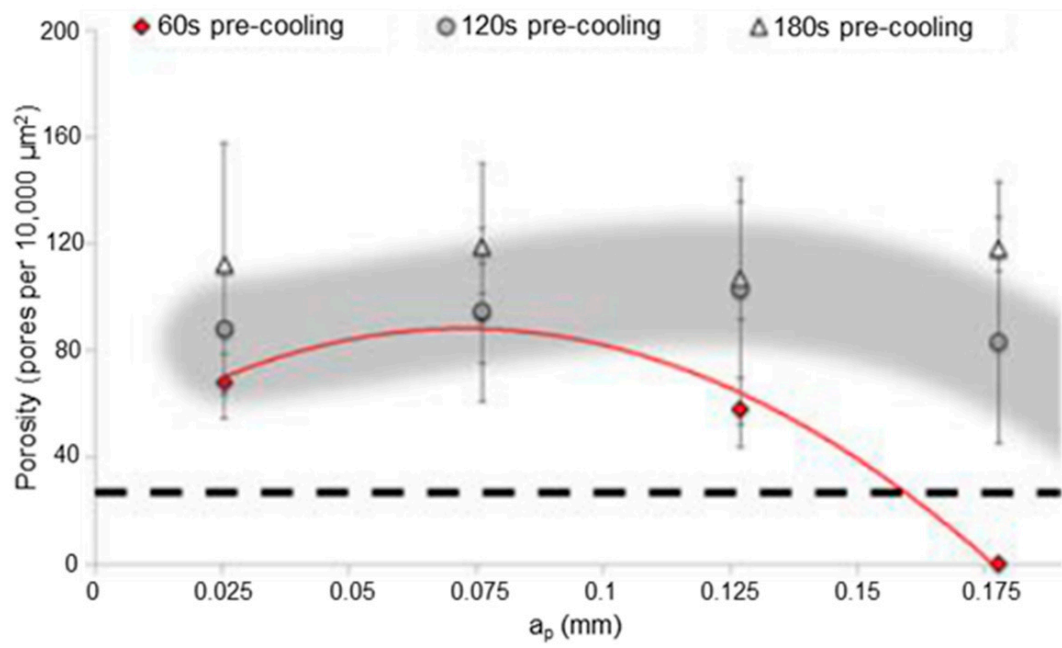

(b)

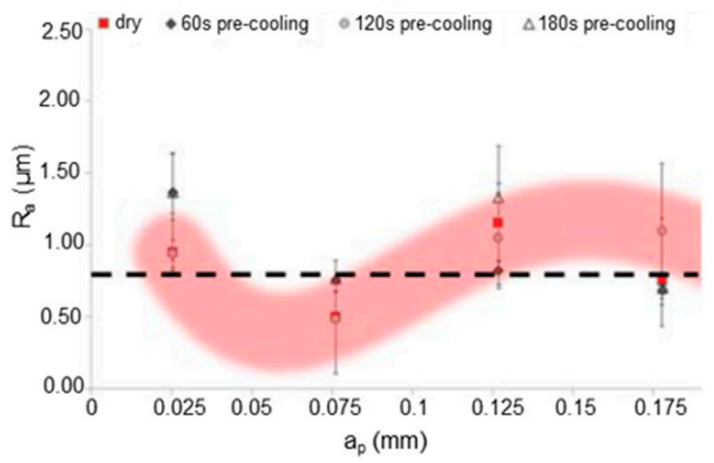

(c)

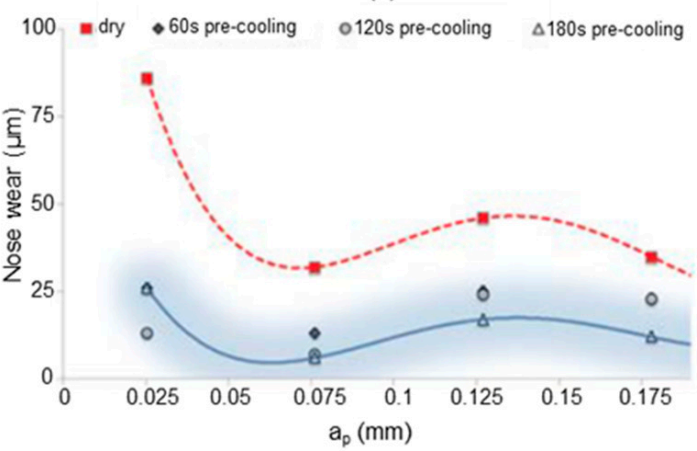

Figure 21. Influence of pre-cooling conditions and depth of cut on (a) surface porosity; (b) surface roughness; (c) nose wear [130]. Adapted with permission from Schoop et al. [130]. Copyright 2016 Taylor \& Francis.

(a)

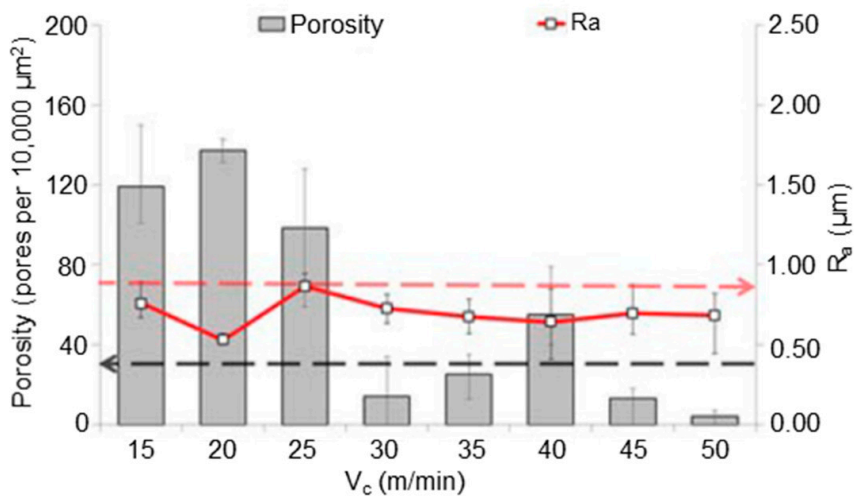

(b)

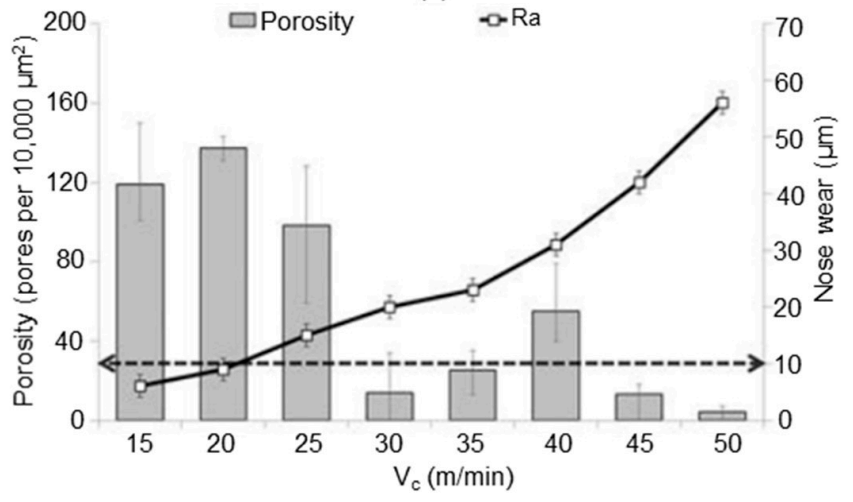

Figure 22. Effect of cutting speed on (a) surface porosity; (b) nose wear [130]. Adapted with permission from Schoop et al. [130]. Copyright 2016 Taylor \& Francis. 


\section{Discussion and Future Research Direction}

Tungsten has unique thermal and mechanical properties, making it a suitable candidate for high-density and high-temperature applications, such as in plasma-facing components. The need for clean energy and advancements in fusion energy generation necessitates the production of parts from tungsten with complex geometries on a large scale. The various areas of research pertaining to tungsten, as identified in this article, have been broadly classified into processing and manufacturing techniques, as shown in Figure 23. The manufacturing methods can be thought of as subtractive techniques, distinguishing them from the processing methods. This classification is used in this section to support the discussion on the different research areas and to offer possible directions for future studies relating to improving tungsten's manufacturability and overall production.

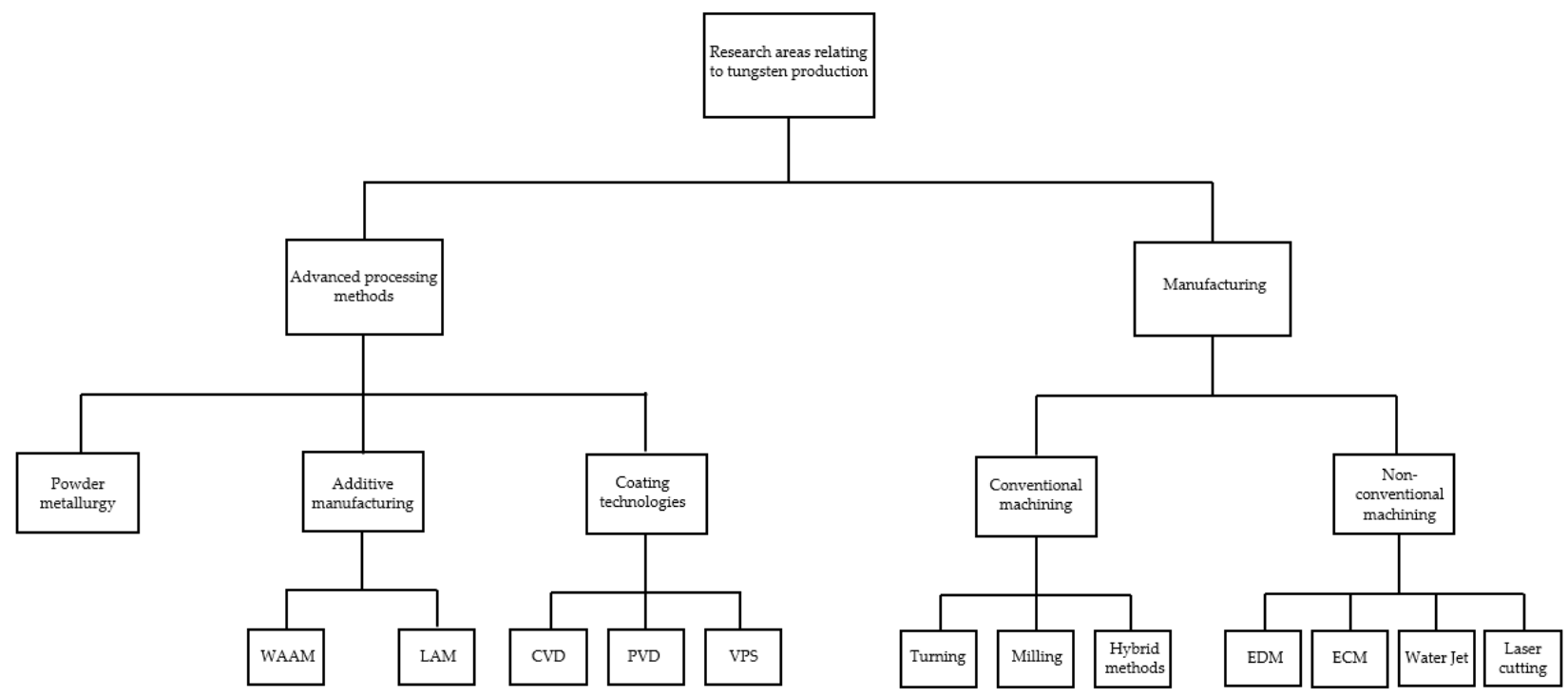

Figure 23. Classification of research areas relating to tungsten production.

The high melting temperature of tungsten renders common processing methods, such as casting, impracticable. Powder metallurgy has traditionally been used to produce nearnet-shaped parts. However, the powder metallurgy process described in Section 3 has limited capability in terms of geometrical complexity and tolerances as well as surface quality.

Additive manufacturing processes, including laser techniques and wire arc additive manufacturing, have recently been used for producing tungsten parts. Whilst these processes allow for the production of large parts with complex components which are not possible with powder metallurgy, there are still significant research gaps in terms of the metallurgical and microstructural aspects of the deposited structures. Further research is necessary to address crack formation and densification issues as major challenges with additively manufactured tungsten components.

CVD, PVD, and VPS are alternative methods used to produce tungsten. However, these techniques are limited to thin layers or films rather than bulk material production. Similarly, as with additively manufactured parts, microstructural considerations (grain size and orientation) and material properties are often causes for concern besides increased cost implication and low production rates. The precise control of the deposition process and post-processing methods, such as post-sintering in a hydrogen atmosphere, can mitigate these drawbacks. This is an area worth examining in addition to the production of parts with adequate thickness.

Irrespective of the processing technology used for producing the near-net-shaped bulk tungsten parts, typically there is a need for a degree of post-process machining to meet the required engineering tolerances and surface quality. As highlighted in Section 2, tungsten is brittle and has a high DBTT, which is dependent on the parts' manufacturing 
route and resulting microstructure. Different methods which have been investigated to enhance the ductility of tungsten include alloying, thermomechanical processing and grain refinement by cold working. In alloying, rhenium is often used but this increases the cost and environmental impact of producing tungsten. Thermomechanical processing and grain refinement methods are alternative routes, requiring high energy input, which is not desirable. Whilst these methods have shown improved ductility, they are still far from ideal and further investigations are necessary since significant brittleness remains in most cases. Future investigations can focus on identifying alternative alloying elements and innovative methods for inducing the thermomechanical processing and grain refinement benefits during additive manufacturing or the powder metallurgy process.

As shown in Figure 23, the machining of tungsten has been categorized into conventional and non-conventional processes. Whilst conventional machining is currently practiced in industry, there is a significant gap in the literature pertaining to this manufacturing route. Specifically, there is no study on drilling and tapping for tungsten parts which are necessary for making functional components. Studies on conventional machining of tungsten can be subdivided into machining of (i) porous and (ii) dense tungsten, both concentrated on turning. Conventional machining of dense tungsten is characterized by a short tool life, a poor surface finish, and high manufacturing costs. There is a limited number of studies investigating the cutting mechanics, tool geometries, and properties. There is also limited focus on the surface integrity of machined layer and the mechanism of deformation. Further studies are necessary to address these and enable economic machining of tungsten. Hybrid methods, such as cryogenic and thermally assisted machining, have shown potential to improve machinability. However, these studies are limited, and further investigations are required to fully characterize the impact of these methods.

Most studies of non-conventional machining of tungsten are concentrated on EDM and ECM. The major challenge in EDM is the high thermal conductivity of tungsten which leads to low material removal rates, high electrode wear, and poor surface integrity. Tungsten forms a protective oxide layer of $\mathrm{WO}_{3}$ which adversely impacts the machining performance in ECM, leading to poor surface integrity and low productivity. Whilst these methods are contactless and overcome the issues related to the high material strength, high hardness, and low ductility of tungsten, they are generally regarded as slow and costly processes with high energy consumption. The non-contact nature of these methods also minimizes issues, such as the built-up residual stresses on the machined surfaces. However, microstructural and surface quality impacts are still areas of concern.

Based on the literature findings, the proposed future direction in the machining of tungsten will require a thorough understanding and consideration of the properties of the material. For example, preheating the material above the DBTT will improve ductility. It is also well known that the strengths of most metals and ceramics degrade with an increase in temperature. The same is true for refractory metals, including tungsten. Figure 24 shows the tensile strength variation with temperature for this group of metals in their unalloyed form. 


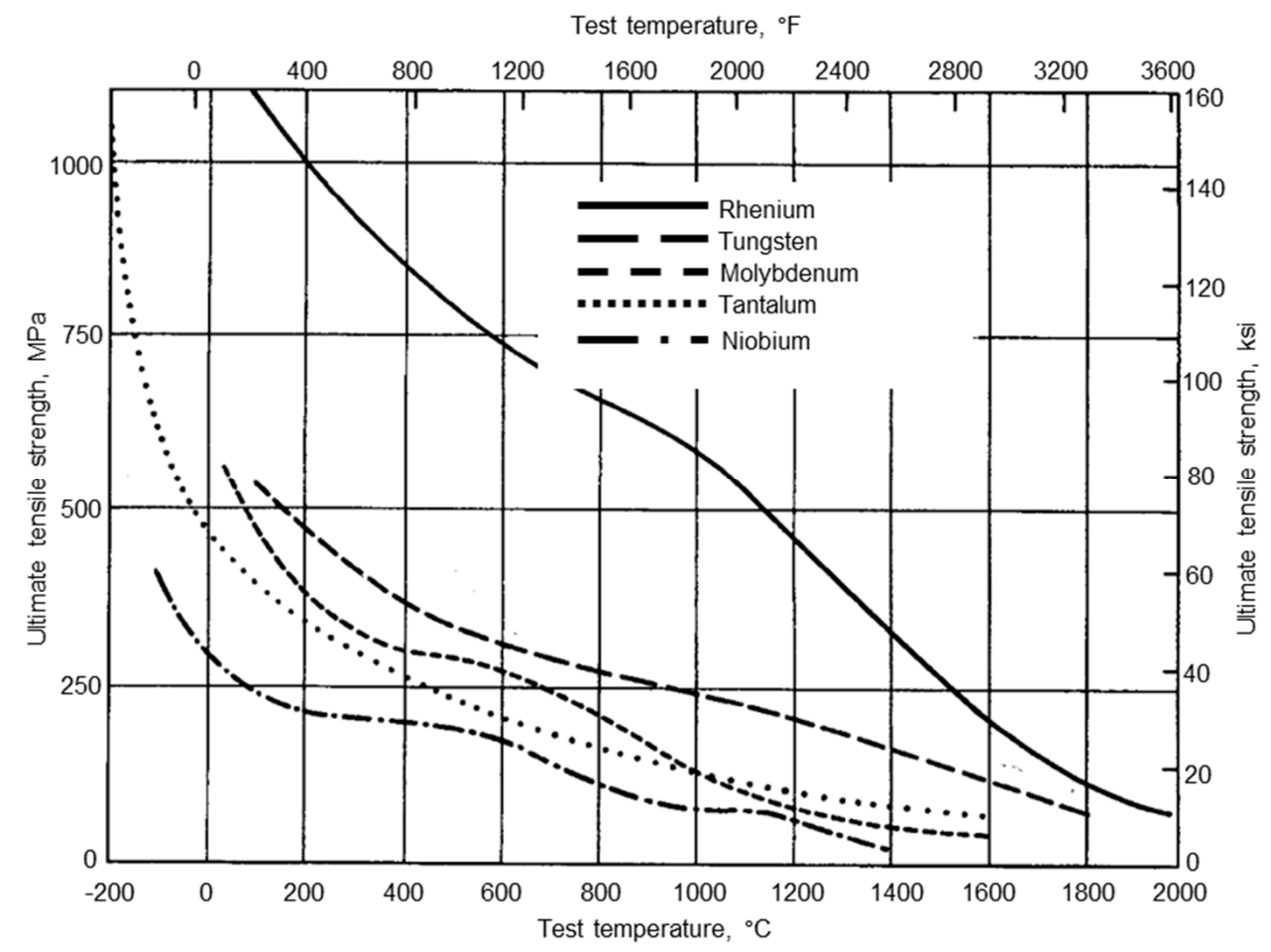

Figure 24. Ultimate tensile strength vs. test temperature for pure (unalloyed) refractory metals [131]. Adapted with permission from Campbell [131]. Copyright 1998 ASM International.

A similar trend has been observed for the effect of temperature on the hardness of tungsten, as shown in Figure 25. The microindentation hardness test was performed by Gibson et al. [132] using a load of $200 \mathrm{~g}$ from $23^{\circ} \mathrm{C}$ to $700^{\circ} \mathrm{C}$. A steep drop in hardness can be seen up to $300^{\circ} \mathrm{C}$, above which the rate of change significantly decreases. Similar observation in the variation of hardness was made by Pisarenko et al. [133]. Hence, preheating tungsten has the effect of not only improving ductility, but also reducing hardness and strength, both of which are properties which have been identified to impede machinability.

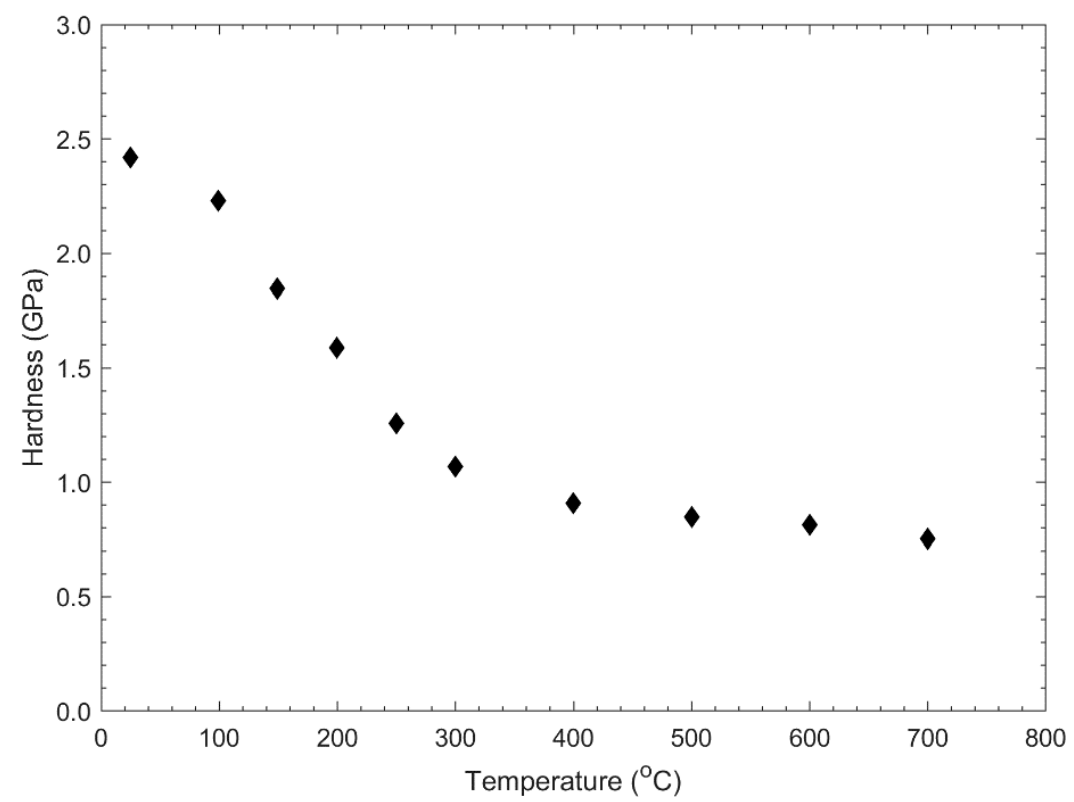

Figure 25. Dependence of the hardness of tungsten on temperature [132]. Adapted with permission from Gibson et al. [132]. Copyright 2015 Elsevier. 
A preheating procedure can be carried out in a controlled manner using a suitably focused, rapid, and high-energy density heat source. Laser and plasma are the most popular sources for such restrictive heating, which limits the heat-affected zone and thermal distortion of the material [134]. The thermal properties of tungsten, especially its high thermal conductivity, low specific heat, and low expansion coefficient, favor this preheating approach [16]. However, the recrystallisation and oxidative tendency of tungsten are foreseen as challenges. The introduction of a preheating temperature coupled with the thermal generation processes during machining can lead to temperatures reaching or exceeding the recrystallisation threshold. To prevent recrystallisation during the forming of tungsten, it is common practice to progressively reduce the process temperature. A similar approach might be followed during this preheating technique, together with a monitoring of the process temperature.

The affinity of tungsten with oxygen to form oxides at high temperatures has been investigated and explained by Gulbransen and Wysong [135] and Cifuentes et al. [136]. Tungsten's relatively low resistance to oxidation has been clearly revealed in these studies, in which temperature has been shown to be the most important factor affecting oxidation. While the metal is stable in dry and humid atmospheric conditions at moderate temperatures, oxidation starts to occur at about $400{ }^{\circ} \mathrm{C}$. The rate of oxidation increases rapidly with temperature and with the sublimation of the $\mathrm{WO}_{3}$ oxide layer occurring above $900{ }^{\circ} \mathrm{C}$ [10]. This sensitivity to oxidation has restricted high-temperature applications of tungsten to protective atmospheric conditions or vacuum and must be taken into consideration for any future research on thermally assisted machining. Moreover, there is a significant gap in cutting tool geometries and cutting parameters for various conventional machining processes.

Whilst heating near or above the DBTT is expected to tackle the issue of tungsten brittleness by promoting machining of the material in its ductile regime, the thermal and chemical tool wear mechanisms should also be taken into account. The mechanism of tool wear was explained in the study by Olsson et al. [123], where cryogenic $\mathrm{LN}_{2}$ cooling produced the best tool life compared to induction-assisted machining. The higher diffusional wear rate in the latter approach is evidence of the thermal influence. Further investigation is necessary to understand the tool wear modes and mechanisms in machining of tungsten.

\section{Conclusions}

In this paper, the challenges of producing tungsten and tungsten alloy parts with complex geometries and required tolerances have been reviewed with respect to current production routes. In general, bulk part production is achieved through powder metallurgy or, more recently, with additive manufacturing, which are associated with poor geometric tolerances. For this reason, some degree of subtractive postprocessing is required to achieve the tolerances associated with engineered parts. However, the poor ductility of tungsten, resulting from its high ductile to brittle transition temperature (DBTT), can make this process incredibly problematic. A review of the literature has also highlighted additional properties which further contribute to this challenge, including the high hardness, material strength, and strain hardening tendency of tungsten. Compared to other metals, the effect of recrystallisation, which increases with deformation, has also been found to inhibit ductility in tungsten. In addition, despite significant progress in reducing the DBTT, processed parts still do not have room-temperature ductility. As such, there remains significant issues with the manufacturing of processed tungsten and tungsten alloy parts through conventional machining. To address these challenges, several unconventional machining methods have also been investigated; however, the surface quality generated through these techniques remains suboptimal. These methods highlight other challenges associated with tungsten stemming from its chemical and thermal properties.

One of the major conclusions from this review is that there is limited literature focused on the manufacturability of tungsten parts, with most existing studies being focused 
on low-temperature machining of porous tungsten or assessment of turning methods. Additionally, existing literature studies rarely place emphasis on enhancing manufacture through improved understanding of its properties. It is believed that the overview of tungsten properties provided in this review paper will be a useful tool in addressing this issue, such that the selection and optimization of future production methods can be based on an effective understanding of the material characteristics. An overview of promising methods based on this understanding has been provided in the future research discussion section of this article.

Author Contributions: Conceptualization, writing, S.O. and A.S.; writing-review and editing, A.L. and S.K. All authors have read and agreed to the published version of the manuscript.

Funding: This work was supported by the UK Atomic Energy Authority with funding from EPSRC Grant EP/T012250/1.

Data Availability Statement: Data sharing is not applicable to this article.

Acknowledgments: The authors acknowledge the support of EPSRC through grant number EP/R513155/1 project 2297674 .

Conflicts of Interest: The authors declare no conflict of interest.

\section{References}

1. International Energy Agency (IEA). World Energy Outlook 2019. 2019. Available online: https://www.iea.org/reports/worldenergy-outlook-2019 (accessed on 12 July 2020).

2. Chu, S.; Majumdar, A. Opportunities and challenges for a sustainable energy future. Nature 2012, 488, 294-303. [CrossRef] [PubMed]

3. Threlfall, R.; King, A.; Bartels, W.; Shulman, J.; Hayes, M. Towards Net Zero: How the World's Largest Companies Report on Climate Risk and Net Zero Transition; KPMG: Amstelveen, The Netherlands, 2020.

4. United Nations Environment Programme. Emissions Gap Report 2020; United Nations Environment Programme: Nairobi, Kenya, 2020.

5. Dresselhaus, M.S.; Thomas, I.L. Alternative energy technologies. Nature 2001, 414, 332-337. [CrossRef] [PubMed]

6. Abernethy, R. Predicting the performance of tungsten in a fusion environment: A literature review. Mater. Sci. Technol. 2017, 33, 388-399. [CrossRef]

7. Ward, D.; Cook, I.; Lechon, Y.; Saez, R. The economic viability of fusion power. Fusion Eng. Des. 2005, 75-79, 1221-1227. [CrossRef]

8. Ueda, Y.; Coenen, J.; De Temmerman, G.; Doerner, R.; Linke, J.; Philipps, V.; Tsitrone, E. Research status and issues of tungsten plasma facing materials for ITER and beyond. Fusion Eng. Des. 2014, 89, 901-906. [CrossRef]

9. Barabash, V.; Peacock, A.; Fabritsiev, S.; Kalinin, G.; Zinkle, S.; Rowcliffe, A.; Rensman, J.-W.; Tavassoli, A.; Marmy, P.; Karditsas, P.; et al. Materials challenges for ITER-Current status and future activities. J. Nucl. Mater. 2007, 367-370, 21-32. [CrossRef]

10. Lassner, E.; Schubert, W.D. Properties, Chemistry, Technology of the Element, Alloys, and Chemical Compounds; Vienna University of Technology: Vienna, Austria, 2005.

11. Bailar, J.C.; Trotman-Dickenson, A.F. (Eds.) Comprehensive Inorganic Chemistry, 4th ed.; Pergamon Press: Oxford, UK, 1973.

12. Holden, N.E. Element 74, the Wolfram versus Tungsten Controversy. In Proceedings of the IUPAC Inorganic Chemistry Division Committee Meeting, Helsinki, Finland, 11-12 August 2008; Brookhaven National Lab.: Upton, NY, USA, 2008.

13. Lennon, A.; Ramesh, K. The thermoviscoplastic response of polycrystalline tungsten in compression. Mater. Sci. Eng. A 2000, 276, 9-21. [CrossRef]

14. Snead, L.L.; Hoelzer, D.T.; Rieth, M.; Nemith, A.A. Refractory Alloys: Vanadium, Niobium, Molybdenum, Tungsten. In Structural Alloys for Nuclear Energy Applications; Elsevier BV: Amsterdam, The Netherlands, 2019; pp. 585-640.

15. Barabash, V. Historical Baseline Document: Appendix A, Materials Design Limit Data; ITER Organization: Saint-Paul-lez-Durance, France, 2012.

16. Tungsten, W. Available online: http:/ / www.matweb.com/search/datasheet_print.aspx?matguid=41e0851d2f3c417ba69ea018 8fa570e3 (accessed on 24 March 2021).

17. Li, H.; Wurster, S.; Motz, C.; Romaner, L.; Draxl, C.; Pippan, R. Dislocation-core symmetry and slip planes in tungsten alloys: Ab initio calculations and microcantilever bending experiments. Acta Mater. 2012, 60, 748-758. [CrossRef]

18. Callister, W.D. Dislocation and Strengthening Mechanisms. In Materials Science and Engineering: An Introduction, 7th ed.; John Wiley \& Sons Inc.: Hoboken, NJ, USA, 2006; pp. 179-180.

19. Liu, A. Lattice Structure and Deformation Mechanisms in Metallic Single Crystals. In Mechanics and Mechanisms of Fracture: An Introduction; ASM International: Almere, The Netherlands, 2005; pp. 357-372.

20. Hirsch, P.B. First suggestion about screws. In Proceedings of the 5th International Conference on Crystallography, Cambridge, UK, 15-24 August 1960; pp. 139-145.

21. Gröger, R.; Bailey, A.G.; Vitek, V. Multiscale modeling of plastic deformation of molybdenum and tungsten: I. Atomistic studies of the core structure and glide of 1/2<1 $11>$ screw dislocations at 0 K. Acta Mater. 2008, 56, 5401-5411. [CrossRef] 
22. Cheng, G.; Xu, W.; Jian, W.; Yuan, H.; Tsai, M.-H.; Zhu, Y.; Zhang, Y.; Millett, P. Dislocations with edge components in nanocrystalline bcc Mo. J. Mater. Res. 2013, 28, 1820-1826. [CrossRef]

23. Setyawan, W.; Kurtz, R.J. Effects of transition metals on the grain boundary cohesion in tungsten. Scr. Mater. 2012, 66, 558-561. [CrossRef]

24. Gludovatz, B.; Wurster, S.; Weingärtner, T.; Hoffmann, A.; Pippan, R. Influence of impurities on the fracture behaviour of tungsten. Philos. Mag. 2011, 91, 3006-3020. [CrossRef]

25. Joshi, a.; Stein, D.F. Intergranular brittleness studies in Tungsten Using Auger Spectroscopy. Metall. Trans. 1970, 1, $2543-2546$.

26. Funkenbusch, A.W.; Bacon, F.; Lee, D. The influence of microstructure on fracture of drawn tungsten wire. Met. Mater. Trans. A 1979, 10, 1085-1091. [CrossRef]

27. Schwartzberg, F.R.; Ogden, H.R.; Jaffee, R.I. Ductile-Brittle Transition in the Refractory Metals; Defense Metals Information Center, Battelle Memorial Institute: Columbus, OH, USA, 1959.

28. Aguirre, M.V.; Martín, A.; Pastor, J.Y.; Llorca, J.; Monge, M.A.; Pareja, R. Mechanical behavior of W-Y2O3 and W-Ti Alloys from $25^{\circ} \mathrm{C}$ to $1000{ }^{\circ} \mathrm{C}$. Metall. Mater. Trans. A Phys. Metall. Mater. Sci. 2009, 40, 2283-2290. [CrossRef]

29. Faleschini, M.; Kreuzer, H.; Kiener, D.; Pippan, R. Fracture toughness investigations of tungsten alloys and SPD tungsten alloys. J. Nucl. Mater. 2007, 367-370, 800-805. [CrossRef]

30. Riedle, J. Bruchwiderstand in Wolfram-Einkristallen: Einfluß der Kristallographischen Orientierung, der Temperatur und der Lastrate; VDI-Verlag: Düsseldorf, Germany, 1995.

31. Yih, S.W.H.; Wang, C.T. Tungsten: Sources, Metallurgy, Properties, and Applications; Plenum Press: New York, NY, USA, $1979 ;$ p. 358.

32. Norajitra, P.; Boccaccini, L.; Diegele, E.; Filatov, V.; Gervash, A.; Giniyatulin, R.; Gordeev, S.; Heinzel, V.; Janeschitz, G.; Konys, J.; et al. Development of a helium-cooled divertor concept: Design-related requirements on materials and fabrication technology. J. Nucl. Mater. 2004, 329-333, 1594-1598. [CrossRef]

33. Ren, C.; Fang, Z.; Koopman, M.; Butler, B.; Paramore, J.; Middlemas, S. Methods for improving ductility of tungsten-A review. Int. J. Refract. Met. Hard Mater. 2018, 75, 170-183. [CrossRef]

34. Shen, T.; Dai, Y.; Lee, Y. Microstructure and tensile properties of tungsten at elevated temperatures. J. Nucl. Mater. 2016, 468, 348-354. [CrossRef]

35. Rupp, D.; Mönig, R.; Gruber, P.; Weygand, S. Fracture toughness and microstructural characterization of polycrystalline rolled tungsten. Int. J. Refract. Met. Hard Mater. 2010, 28, 669-673. [CrossRef]

36. Reiser, J.; Hoffmann, J.; Jäntsch, U.; Klimenkov, M.; Bonk, S.; Bonnekoh, C.; Rieth, M.; Hoffmann, A.; Mrotzek, T. Ductilisation of tungsten (W): On the shift of the brittle-to-ductile transition (BDT) to lower temperatures through cold rolling. Int. J. Refract. Met. Hard Mater. 2016, 54, 351-369. [CrossRef]

37. Wei, Q.; Kecskes, L. Effect of low-temperature rolling on the tensile behavior of commercially pure tungsten. Mater. Sci. Eng. A 2008, 491, 62-69. [CrossRef]

38. Zhang, X.; Yan, Q.; Lang, S.; Xia, M.; Ge, C. Texture evolution and basic thermal-mechanical properties of pure tungsten under various rolling reductions. J. Nucl. Mater. 2016, 468, 339-347. [CrossRef]

39. Hall, E.O. The Deformation and Ageing of Mild Steel: III Discussion of Results. Proc. Phys. Soc. Sect. B 1951, 64, 747. [CrossRef]

40. Petch, N.J. The cleavage strength of polycrystals. J. Iron Steel Inst. 1953, 174, 25-28.

41. Vashi, U.K.; Armstrong, R.W.; Zima, G.E. The hardness and grain size of consolidated fine tungsten powder. Met. Mater. Trans. A 1970, 1, 1769-1771. [CrossRef]

42. Reiser, J.; Rieth, M.; Dafferner, B.; Hoffmann, A.; Yi, X.; Armstrong, D.E. Tungsten foil laminate for structural divertor applicationsAnalyses and characterisation of tungsten foil. J. Nucl. Mater. 2012, 424, 197-203. [CrossRef]

43. Terentyev, D.; Xiao, X.; Dubinko, A.; Bakaeva, A.; Duan, H. Dislocation-mediated strain hardening in tungsten: Thermomechanical plasticity theory and experimental validation. J. Mech. Phys. Solids 2015, 85, 1-15. [CrossRef]

44. Romaner, L.; Draxl, C.; Pippan, R. Effect of Rhenium on the Dislocation Core Structure in Tungsten. Phys. Rev. Lett. 2010, 104, 195503. [CrossRef] [PubMed]

45. Stephens, J.R. Dislocation structures in single-crystal tungsten and tungsten alloys. Met. Mater. Trans. A 1970, 1, 1293-1301. [CrossRef]

46. Geach, G.A.; Hughes, J.E. The alloys of rhenium with molybdenum or with tungsten and having good high temperature properties. In Plansee Proceedings; Pergamon Press: London, UK, 1955; pp. 245-253.

47. Mutoh, Y.; Ichikawa, K.; Nagata, K.; Takeuchi, M. Effect of rhenium addition on fracture toughness of tungsten at elevated temperatures. J. Mater. Sci. 1995, 30, 770-775. [CrossRef]

48. Wurster, S.; Gludovatz, B.; Pippan, R. High temperature fracture experiments on tungsten-rhenium alloys. Int. J. Refract. Met. Hard Mater. 2010, 28, 692-697. [CrossRef]

49. Watanabe, S.; Nogami, S.; Reiser, J.; Rieth, M.; Sickinger, S.; Baumgärtner, S.; Miyazawa, T.; Hasegawa, A. Tensile and impact properties of tungsten-rhenium alloy for plasma-facing components in fusion reactor. Fusion Eng. Des. 2019, 148, 111323. [CrossRef]

50. Klopp, W.D.; Witzke, W.R.; Raffo, P.L. Mechanical Dilute Properties of and Tungsten-Rhenium; National Aeronautics and Space Administration: Washington, DC, USA, September 1966. 
51. Wurster, S.; Baluc, N.; Battabyal, M.; Crosby, T.; Du, J.; García-Rosales, C.; Hasegawa, A.; Hoffmann, A.; Kimura, A.; Kurishita, H.; et al. Recent progress in R\&D on tungsten alloys for divertor structural and plasma facing materials. J. Nucl. Mater. 2013, 442, S181-S189. [CrossRef]

52. El-Guebaly, L.; Kurtz, R.; Rieth, M.; Kurishita, H.; Robinson, A.; Team, A. W-Based Alloys for Advanced Divertor Designs: Options and Environmental Impact of State-of-the-Art Alloys. Fusion Sci. Technol. 2011, 60, 185-189. [CrossRef]

53. Fang, Z.Z.; Ren, C.; Simmons, M.; Sun, P. The effect of Ni doping on the mechanical behavior of tungsten. Int. J. Refract. Met. Hard Mater. 2020, 92, 105281. [CrossRef]

54. Ren, C.; Fang, Z.Z.; Koopman, M.; Zhang, H. The Effects of Molybdenum Additions on the Sintering and Mechanical Behavior of Ultrafine-Grained Tungsten. JOM 2018, 70, 2567-2573. [CrossRef]

55. Patra, A.; Saxena, R.; Karak, S. Combined effect of Ni and nano- $\mathrm{Y}_{2} \mathrm{O}_{3}$ addition on microstructure, mechanical and high temperature behavior of mechanically alloyed W-Mo. Int. J. Refract. Met. Hard Mater. 2016, 60, 131-146. [CrossRef]

56. Wurster, S.; Gludovatz, B.; Hoffmann, A.; Pippan, R. Fracture behaviour of tungsten-vanadium and tungsten-tantalum alloys and composites. J. Nucl. Mater. 2011, 413, 166-176. [CrossRef]

57. Rieth, M.; Reister, J.; Dafferner, B.; Baumgärtner, S. The Impact of Refractory Material Properties on the Helium Cooled Divertor Design. Fusion Sci. Technol. 2012, 61, 381-384. [CrossRef]

58. Bose, A.; Schuh, C.A.; Tobia, J.C.; Tuncer, N.; Mykulowycz, N.M.; Preston, A.; Barbati, A.C.; Kernan, B.; Gibson, M.A.; Krause, D.; et al. Traditional and additive manufacturing of a new Tungsten heavy alloy alternative. Int. J. Refract. Met. Hard Mater. 2018, 73, 22-28. [CrossRef]

59. Ye, H.; Liu, X.Y.; Hong, H. Fabrication of metal matrix composites by metal injection molding-A review. J. Mater. Process. Technol. 2008, 200, 12-24. [CrossRef]

60. Blagoeva, D.T.; Opschoor, J.; Pintsuk, G.; Sarbu, C. Development and Qualification of Tungsten and Tungsten Alloys for Fusion Fusion Sci. Technol. 2013, 64, 203-210. [CrossRef]

61. Piotter, V.; Zeep, B.; Norajitra, P.; Ruprecht, R.; von der Weth, A.; Hausselt, J. Development of a powder metallurgy process for tungsten components. Fusion Eng. Des. 2008, 83, 1517-1520. [CrossRef]

62. Zeep, B.; Norajitra, P.; Piotter, V.; Boehm, J.; Ruprecht, R.; Hausselt, J. Net shaping of tungsten components by micro powder injection moulding. Fusion Eng. Des. 2007, 82, 2660-2665. [CrossRef]

63. Antusch, S.; Norajitra, P.; Piotter, V.; Ritzhaupt-Kleissl, H.-J.; Spatafora, L. Powder Injection Molding-An innovative manufacturing method for He-cooled DEMO divertor components. Fusion Eng. Des. 2011, 86, 1575-1578. [CrossRef]

64. Suryanarayana, C. Mechanical Alloying and Milling; Cambridge International Science Publishing, Limited: Cambridge, UK, 2004; Volume 46, pp. 1-184. [CrossRef]

65. Oghbaei, M.; Mirzaee, O. Microwave versus conventional sintering: A review of fundamentals, advantages and applications J. Alloy. Compd. 2010, 494, 175-189. [CrossRef]

66. Li, Y.; Hu, K.; Li, X.; Ai, X.; Qu, S. Fine-grained 93W-5.6Ni-1.4Fe heavy alloys with enhanced performance prepared by spark plasma sintering. Mater. Sci. Eng. A 2013, 573, 245-252. [CrossRef]

67. Caldwell, S.G.; Bose, A.; Dowding, R.J. (Eds.) Tungsten \& Tungsten Alloys-1992. In Proceedings of the First International Conference on Tungsten and Tungsten Alloys, Princeton, NJ, USA, 1 January 1993; pp. 89-96.

68. Şahin, Y. Recent Progress in Processing of Tungsten Heavy Alloys. J. Powder Technol. 2014, 2014, 1-22. [CrossRef]

69. Edstrom, C.M.; Phillips, A.G.; Johnson, L.D.; Corle, R.R. Literature on Fabrication of Tungtsen for Application in Pyrochemical Processing of Spent Nuclear Fuels; Technical Report No. RFP-2864; Rockwell International Corp.: Golden, CO, USA, 1980.

70. Marinelli, G.; Martina, F.; Lewtas, H.; Hancock, D.; Mehraban, S.; Lavery, N.P.; Ganguly, S.; Williams, S. Microstructure and thermal properties of unalloyed tungsten deposited by Wire + Arc Additive Manufacture. J. Nucl. Mater. 2019, 522, 45-53. [CrossRef]

71. Marinelli, G.; Martina, F.; Ganguly, S.; Williams, S. Development of Wire + Arc additive manufacture for the production of large-scale unalloyed tungsten components. Int. J. Refract. Met. Hard Mater. 2019, 82, 329-335. [CrossRef]

72. Lv, Y.; Lian, Y.; Song, J.; Yu, Y.; Liu, X.; Zhuang, Z. WITHDRAWN: The thermal properties of high purity and fully dense tungsten produced by chemical vapor deposition. J. Nucl. Mater. 2014, 457, 317-323. [CrossRef]

73. Niu, Y.; Zheng, X.; Ji, H.; Qi, L.; Ding, C.; Chen, J.; Luo, G. Microstructure and thermal property of tungsten coatings prepared by vacuum plasma spraying technology. Fusion Eng. Des. 2010, 85, 1521-1526. [CrossRef]

74. Wang, D.; Yu, C.; Zhou, X.; Ma, J.; Liu, W.; Shen, Z. Dense Pure Tungsten Fabricated by Selective Laser Melting. Appl. Sci. 2017, 7, 430. [CrossRef]

75. Braun, J.; Kaserer, L.; Stajkovic, J.; Leitz, K.-H.; Tabernig, B.; Singer, P.; Leibenguth, P.; Gspan, C.; Kestler, H.; Leichtfried, G. Molybdenum and tungsten manufactured by selective laser melting: Analysis of defect structure and solidification mechanisms. Int. J. Refract. Met. Hard Mater. 2019, 84, 104999. [CrossRef]

76. Iveković, A.; Omidvari, N.; Vrancken, B.; Lietaert, K.; Thijs, L.; Vanmeensel, K.; Vleugels, J.; Kruth, J.-P. Selective laser melting of tungsten and tungsten alloys. Int. J. Refract. Met. Hard Mater. 2018, 72, 27-32. [CrossRef]

77. Nie, B.; Yang, L.; Huang, H.; Bai, S.; Wan, P.; Liu, J. Femtosecond laser additive manufacturing of iron and tungsten parts. Appl. Phys. A 2015, 119, 1075-1080. [CrossRef]

78. Zhou, X.; Liu, X.; Zhang, D.; Shen, Z.; Liu, W. Balling phenomena in selective laser melted tungsten. J. Mater. Process. Technol. 2015, 222, 33-42. [CrossRef] 
79. Guan, K.; Wang, Z.; Gao, M.; Li, X.; Zeng, X. Effects of processing parameters on tensile properties of selective laser melted 304 stainless steel. Mater. Des. 2013, 50, 581-586. [CrossRef]

80. Wang, M.; Li, R.; Yuan, T.; Chen, C.; Zhang, M.; Weng, Q.; Yuan, J. Selective laser melting of W-Ni-Cu composite powder: Densification, microstructure evolution and nano-crystalline formation. Int. J. Refract. Met. Hard Mater. 2018, 70, 9-18. [CrossRef]

81. Wang, X.; Wraith, M.; Burke, S.; Rathbun, H.; DeVlugt, K. Densification of W-Ni-Fe powders using laser sintering. Int. J. Refract. Met. Hard Mater. 2016, 56, 145-150. [CrossRef]

82. Field, A.C.; Carter, L.N.; Adkins, N.J.E.; Attallah, M.M.; Gorley, M.J.; Strangwood, M. The Effect of Powder Characteristics on Build Quality of High-Purity Tungsten Produced via Laser Powder Bed Fusion (LPBF). Met. Mater. Trans. A 2020, 51, 1367-1378. [CrossRef]

83. Zhang, D.; Cai, Q.; Liu, J. Formation of Nanocrystalline Tungsten by Selective Laser Melting of Tungsten Powder. Mater. Manuf. Process. 2012, 27, 1267-1270. [CrossRef]

84. Dorow-Gerspach, D.; Kirchner, A.; Loewenhoff, T.; Pintsuk, G.; Weißgärber, T.; Wirtz, M. Additive manufacturing of high density pure tungsten by electron beam melting. Nucl. Mater. Energy 2021, 28, 101046. [CrossRef]

85. Neiser, R.A.; Smolik, G.R.; Hollis, K.J.; Watson, R.D. Evaluation of plasma-sprayed tungsten for fusion reactors. J. Therm. Spray Technol. 1993, 2, 393-399. [CrossRef]

86. Sato, K.; Nakamura, K.; Suzuki, S.; Araki, M.; Dairaku, M.; Yokoyama, K.; Akiba, M. High Heat Flux Test of CVD-Tungsten Coated Cu Heat Sink Divertor Mock-Up. Fusion Technol. 1996, 30, 769-773. [CrossRef]

87. Nakamura, K.; Suzuki, S.; Satoh, K.; Araki, M.; Yokoyama, K.; Dairaku, M.; Akiba, M. Erosion of CFCs and W at high temperature under high heat loads. J. Nucl. Mater. 1994, 212-215, 1201-1205. [CrossRef]

88. Smid, I.; Akiba, M.; Vieider, G.; Plöchl, L. Development of tungsten armor and bonding to copper for plasma-interactive components. J. Nucl. Mater. 1998, 258-263, 160-172. [CrossRef]

89. Salhi, Z.; Klein, D.; Gougeon, P.; Coddet, C. Development of coating by thermal plasma spraying under very low-pressure condition. Vacuum 2005, 77, 145-150. [CrossRef]

90. Matejicek, J.; Chráska, P.; Linke, J. Thermal Spray Coatings for Fusion Applications-Review. J. Therm. Spray Technol. 2007, 16, 64-83. [CrossRef]

91. Murphy, J.; Giannattasio, A.; Yao, Z.; Hetherington, C.; Nellist, P.; Roberts, S. The mechanical properties of tungsten grown by chemical vapour deposition. J. Nucl. Mater. 2009, 386-388, 583-586. [CrossRef]

92. Giannattasio, A.; Roberts, S. Strain-rate dependence of the brittle-to-ductile transition temperature in tungsten. Philos. Mag. 2007, 87, 2589-2598. [CrossRef]

93. Lassila, D.H.; Connor, A. Tungsten and Tungsten Alloys-Recent Advances; The Minerals, Metals and Materials Society: Warrendale, PA, USA, 1991; pp. 79-85.

94. Rieth, M.; Dudarev, S.; de Vicente, S.G.; Aktaa, J.; Ahlgren, T.; Antusch, S.; Armstrong, D.; Balden, M.; Baluc, N.; Barthe, M.-F.; et al. Recent progress in research on tungsten materials for nuclear fusion applications in Europe. J. Nucl. Mater. 2013, 432, 482-500. [CrossRef]

95. Krauss, W.; Holstein, N.; Konys, J.; Mazul, I. Investigation of the impact of fabrication methods on the microstructure features of W-components of a He-cooled divertor. Fusion Eng. Des. 2005, 81, 259-264. [CrossRef]

96. Holstein, N.; Krauss, W.; Konys, J. Development of novel tungsten processing technologies for electro-chemical machining (ECM) of plasma facing components. Fusion Eng. Des. 2011, 86, 1611-1615. [CrossRef]

97. Ho, K.; Newman, S. State of the art electrical discharge machining (EDM). Int. J. Mach. Tools Manuf. 2003, 43, 1287-1300. [CrossRef]

98. Sundaram, M.; Rajurkar, K. Electrical and Electrochemical Processes. In Intelligent Energy Field Manufacturing; CRC Press: Boca Raton, FL, USA, 2010; pp. 173-212.

99. Wang, Y.; Wang, L.; Zhang, X.; Mou, N.; Yao, D. Cutting of tungsten plate for fusion device via pre-mixed abrasive water jet. Fusion Eng. Des. 2020, 159, 111790. [CrossRef]

100. Šniaukas, R.; Račiukaitis, G. Laser Micro-Cutting of Thick Tungsten Sheets. In Proceedings of the Lasers in Manufacturing Conference 2015, Munich, Germany, 22-25 June 2015.

101. Begic-Hajdarevic, D.; Vucijak, B.; Pasic, M.; Bijelonja, I. Analysis of the influence of cutting parameters on surface roughness in laser cutting of tungsten alloy using control charts. Teh. Vjesn.-Tech. Gaz. 2017, 24, 339-344. [CrossRef]

102. Uebel, M.; Bliedtner, J. Laser Precision Cutting of High-melting Metal Foils. Procedia Eng. 2014, 69, 99-103. [CrossRef]

103. Spiro, A.; Lowe, M.; Pasmanik, G. Drilling rate of five metals with picosecond laser pulses at 355, 532, and $1064 \mathrm{~nm}$. Appl. Phys. A 2012, 107, 801-808. [CrossRef]

104. Begic-Hajdarevic, D.; Bijelonja, I. Experimental and Numerical Investigation of Temperature Distribution and Hole Geometry during Laser Drilling Process. Procedia Eng. 2015, 100, 384-393. [CrossRef]

105. König, W.; Dauw, D.; Levy, G.; Panten, U. EDM-Future Steps towards the Machining of Ceramics. CIRP Ann. 1988, 37, 623-631. [CrossRef]

106. Masuzawa, T. State of the Art of Micromachining. CIRP Ann. 2000, 49, 473-488. [CrossRef]

107. Liu, Y.; Zhao, F.; Sundaram, M.M.; Rajurkar, K.P. Study on the surface integrity of machined tool in micro EDM. In Proceedings of the 16th International Symposium on Electromachining, Shanghai, China, 19-23 April 2010; pp. 685-689.

108. Krauss, W.; Holstein, N.; Konys, J. Development and fabrication aspects regarding tungsten components for a He-cooled divertor. Fusion Eng. Des. 2005, 75-79, 775-778. [CrossRef] 
109. Han, W.; Kunieda, M. A novel method to switch machining mode between Micro-ECM and Micro-EDM using oxide film on surface of tungsten electrode. Precis. Eng. 2019, 56, 455-465. [CrossRef]

110. Rajurkar, K.; Zhu, D.; McGeough, J.; Kozak, J.; De Silva, A. New Developments in Electro-Chemical Machining. CIRP Ann. 1999, 48, 567-579. [CrossRef]

111. McGeough, J.A. Principles of Electrochemical Machining; Chapman \& Hall: London, UK, 1974.

112. Krauss, W.; Holstein, N.; Konys, J. Strategies in electro-chemical machining of tungsten for divertor application. Fusion Eng. Des. 2007, 82, 1799-1805. [CrossRef]

113. Zhang, C.; Zhang, Y.; Chen, X.; Li, W.; Liu, G. Investigation of the electrochemical dissolution behavior of tungsten during electrochemical machining. Int. J. Adv. Manuf. Technol. 2018, 97, 3575-3582. [CrossRef]

114. Fan, Z.-W.; Hourng, L.-W.; Wang, C.-Y. Fabrication of tungsten microelectrodes using pulsed electrochemical machining. Precis. Eng. 2010, 34, 489-496. [CrossRef]

115. Liu, Z.; Zeng, Y.; Zhang, W. Fabrication of metal microtool applying wire electrochemical machining. Adv. Mech. Eng. 2014, 6, 382105. [CrossRef]

116. He, H.; Zeng, Y.; Qu, N. An investigation into wire electrochemical micro machining of pure tungsten. Precis. Eng. 2016, 45, 285-291. [CrossRef]

117. Lauer, B.; Jäggi, B.; Neuenschwander, B. Influence of the Pulse Duration onto the Material Removal Rate and Machining Quality for Different Types of Steel. Phys. Procedia 2014, 56, 963-972. [CrossRef]

118. Klancnik, S.; Begic-Hajdarevic, D.; Paulic, M.; Ficko, M.; Cekic, A.; Husic, M.C. Prediction of Laser Cut Quality for Tungsten Alloy Using the Neural Network Method. Stroj. Vestn. J. Mech. Eng. 2015, 61, 714-720. [CrossRef]

119. Shokrani, A.; Dhokia, V.; Newman, S. Environmentally conscious machining of difficult-to-machine materials with regard to cutting fluids. Int. J. Mach. Tools Manuf. 2012, 57, 83-101. [CrossRef]

120. Zhong, L.; Li, L.; Wu, X.; He, N. Micro cutting of pure tungsten using self-developed polycrystalline diamond slotting tools. Int. J. Adv. Manuf. Technol. 2016, 89, 2435-2445. [CrossRef]

121. Legutko, S.; Winiarski, P.; Chwalczuk, T.; Marcincinova-Novakova, L.; Zak, K. Tool life of ceramic wedges during precise turning of tungsten. In Proceedings of the MATEC Web of Conferences; EDP Sciences: Les Ulis, France, 2017; pp. 1-9.

122. Olsson, M.; Bushlya, V.; Lenrick, F.; Ståhl, J.-E. Evaluation of tool wear mechanisms and tool performance in machining single-phase tungsten. Int. J. Refract. Met. Hard Mater. 2021, 94, 105379. [CrossRef]

123. Olsson, M.; Akujärvi, V.; Ståhl, J.E.; Bushlya, V. Cryogenic and hybrid induction-assisted machining strategies as alternatives for conventional machining of refractory tungsten and niobium. Int. J. Refract. Met. Hard Mater. 2021, 97, 105520. [CrossRef]

124. Pusavec, F. Porous tungsten machining under cryogenic conditions. Int. J. Refract. Met. Hard Mater. 2012, 35, 84-89. [CrossRef]

125. Das, J.; Chakraborty, A.; Bagchi, T.; Sarma, B. Improvement of machinability of tungsten by copper infiltration technique. Int. J. Refract. Met. Hard Mater. 2008, 26, 530-539. [CrossRef]

126. Tarter, J.O.; Effgen, M.; Pušavec, F.; Jawahir, I. Cryogenic machining of porous tungsten for dispenser cathode applications. In Proceedings of the 2008 IEEE International Vacuum Electronics Conference, Monterey, CA, USA, 22-24 April 2008; IEEE: Piscataway, NJ, USA, 2008; pp. 293-294.

127. Nee, A.; Song, B.; Ong, S. Re-engineering Manufacturing for Sustainability. In Proceedings of the 20th CIRP International Conference on Life Cycle Engineering, Singapore, 17-19 April 2013.

128. Schoop, J.; Ambrosy, F.; Zanger, F.; Schulze, V.; Balk, T.; Jawahir, I. Cryogenic machining of porous tungsten for enhanced surface integrity. J. Mater. Process. Technol. 2016, 229, 614-621. [CrossRef]

129. Schoop, J.; Effgen, M.; Balk, T.; Jawahir, I. The Effects of Depth of Cut and Pre-cooling on Surface Porosity in Cryogenic Machining of Porous Tungsten. Procedia CIRP 2013, 8, 357-362. [CrossRef]

130. Schoop, J.; Ambrosy, F.; Zanger, F.; Schulze, V.; Jawahir, I.S.; Balk, T.J. Increased Surface Integrity in Porous Tungsten from Cryogenic Machining with Cermet Cutting Tool. Mater. Manuf. Process. 2016, 31, 823-831. [CrossRef]

131. Campbell, F.C. Refractory Metals and Alloys. In Metals Handbook Desk Edition; ASM International: Almere, The Netherlands, 1998; pp. 629-633.

132. Gibson, J.S.-L.; Roberts, S.; Armstrong, D. High temperature indentation of helium-implanted tungsten. Mater. Sci. Eng. A 2015, 625, 380-384. [CrossRef]

133. Pisarenko, G.S.; Borisenko, V.A.; Kashtalyan, Y.A. The effect of temperature on the hardness and modulus of elasticity of tungsten and molybdenum $\left(20-2700^{\circ} \mathrm{C}\right)$. Powder Metall. Met. Ceram. 1964, 1, 371-374. [CrossRef]

134. Sun, S.; Brandt, M.; Dargusch, M. Thermally enhanced machining of hard-to-machine materials-A review. Int. J. Mach. Tools Manuf. 2010, 50, 663-680. [CrossRef]

135. Gulbransen, E.A.; Wysong, W.S. Thin Oxide Films on Tungsten. Met. Technol. 1947, 14, 611-627.

136. Cifuentes, S.C.; Monge, M.A.; Pérez, P. On the oxidation mechanism of pure tungsten in the temperature range $600-800{ }^{\circ} \mathrm{C}$. Corros. Sci. 2012, 57, 114-121. [CrossRef] 